THREE DIMENSIONAL VOLCANO-ACOUSTIC SOURCE LOCALIZATION AT

KARYMSKY VOLCANO, KAMCHATKA, RUSSIA

By

Colin R. Rowell

RECOMMENDED:

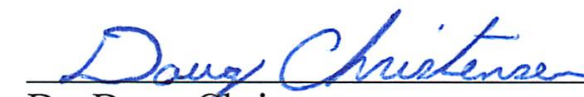

Dr. Doug Christengen

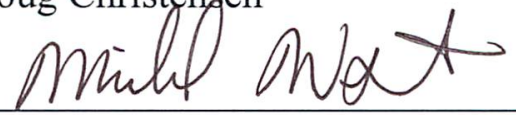

Dr. Michael West

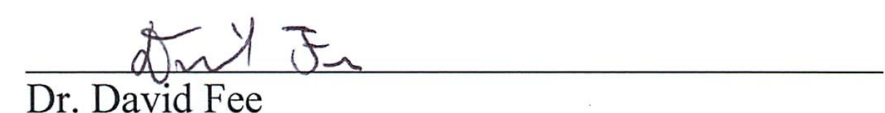

Advisory Committee Chair

APPROVED:

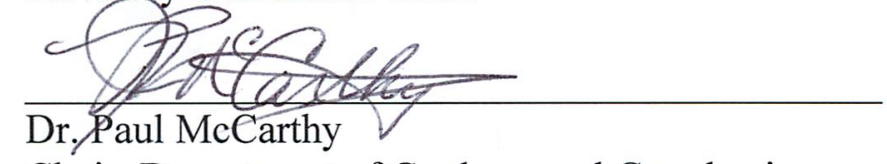

Chair, Department of Geology and Geophysics

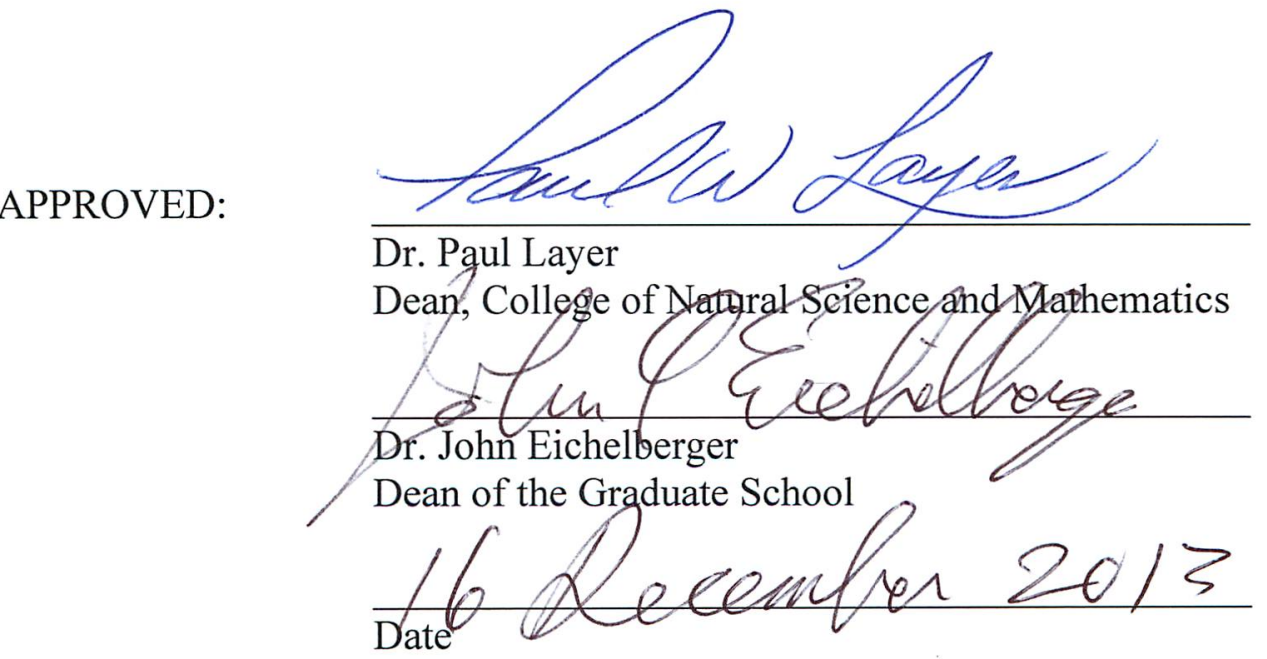





\title{
THREE DIMENSIONAL VOLCANO-ACOUSTIC SOURCE LOCALIZATION AT KARYMSKY VOLCANO, KAMCHATKA, RUSSIA
}

\author{
A \\ THESIS \\ Presented to the faculty \\ of the University of Alaska Fairbanks \\ in Partial Fulfillment of the Requirements \\ for the degree of
}

MASTER OF SCIENCE

By

Colin Rowell, B.S.

Fairbanks, Alaska

December 2013 


\begin{abstract}
We test two methods of 3-D acoustic source localization on volcanic explosions and small-scale jetting events at Karymsky Volcano, Kamchatka, Russia. Recent infrasound studies have provided evidence that volcanic jets produce low-frequency aerodynamic sound (jet noise) similar to that from man-made jet engines. Man-made jets are known to produce sound through turbulence along the jet axis, but discrimination of sources along the axis of a volcanic jet requires a network of sufficient topographic relief to attain resolution in the vertical dimension. At Karymsky Volcano, the topography of an eroded edifice adjacent to the active cone provided a platform for the atypical deployment of five infrasound sensors with intra-network relief of $\sim 600 \mathrm{~m}$ in July 2012. A novel 3-D inverse localization method, srcLoc, is tested and compared against a more common grid-search semblance technique. Simulations using synthetic signals indicate that srcLoc is capable of determining vertical source locations for this network configuration to within $\pm 150 \mathrm{~m}$ or better. However, srcLoc locations for explosions and jetting at Karymsky Volcano show a persistent overestimation of source elevation and underestimation of sound speed by an average of $\sim 330 \mathrm{~m}$ and $25 \mathrm{~m} / \mathrm{s}$, respectively. The semblance method is able to produce more realistic source locations by fixing the sound speed to expected values of $335-340 \mathrm{~m} / \mathrm{s}$. The consistency of location errors for both explosions and jetting activity over a wide range of wind and temperature conditions points to the influence of topography. Explosion waveforms exhibit amplitude relationships and waveform distortion strikingly similar to those theorized by modeling studies of wave diffraction around the crater rim. We suggest delay of signals and apparent elevated source locations are due to altered raypaths and/or crater diffraction effects. Our results suggest the influence of topography in the vent region must be accounted for when attempting 3-D volcano acoustic source localization. Though the data presented here are insufficient to resolve noise sources for these jets, which are much smaller in scale than those of previous volcanic jet noise studies, similar techniques may be successfully applied to large volcanic jets in the future.
\end{abstract}





\section{Table of Contents}

Page

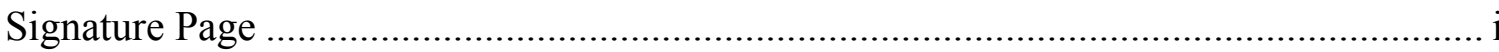

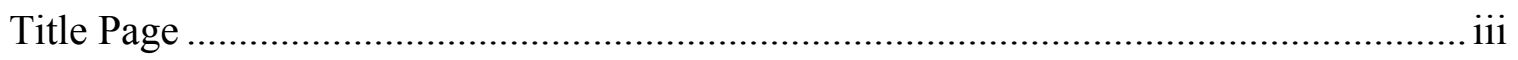

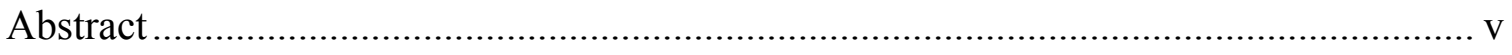

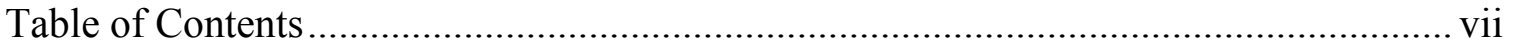

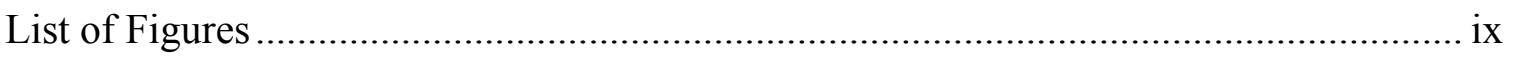

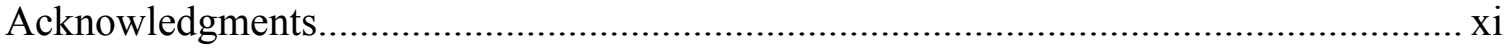

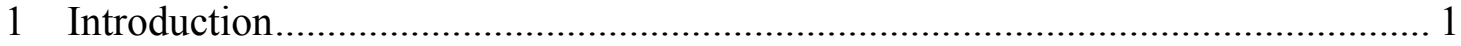

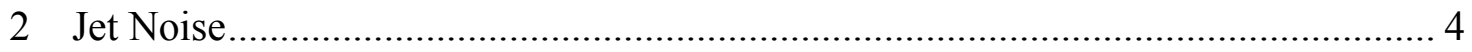

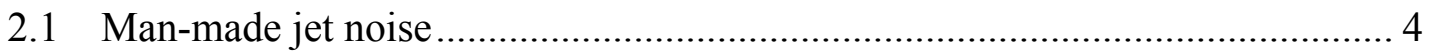

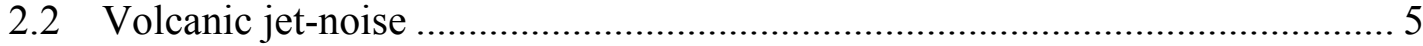

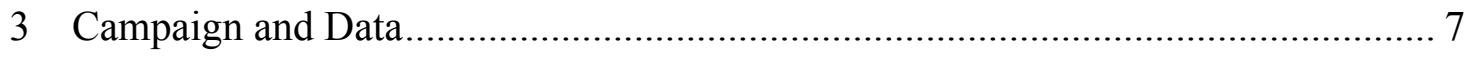

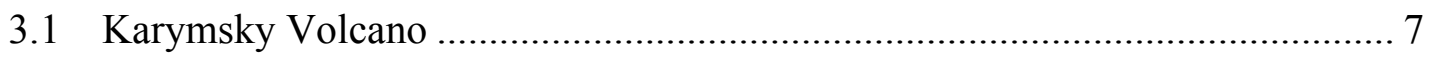

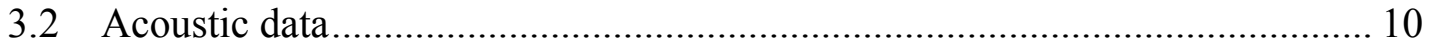

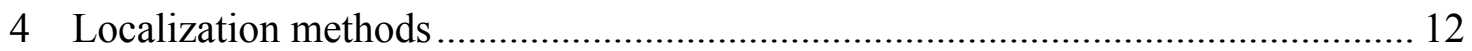

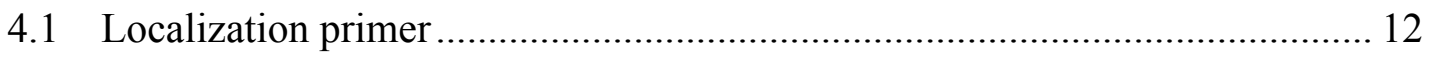

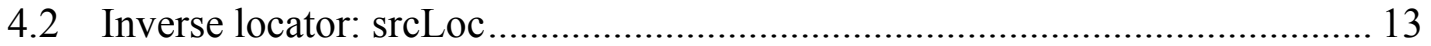

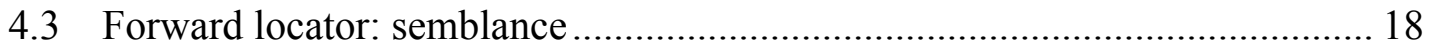

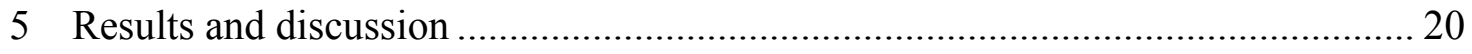

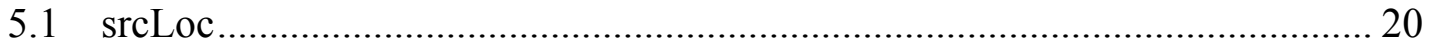

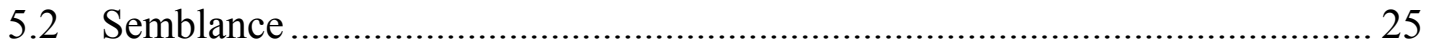

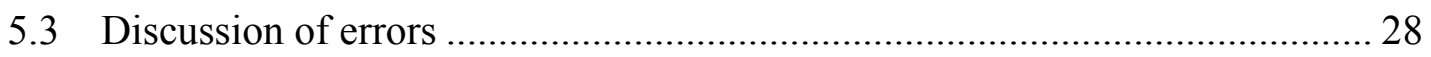

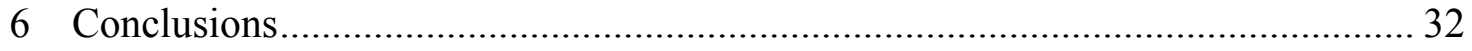

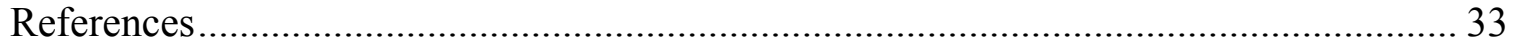





\section{List of Figures}

Page

Figure 1. Location of Karymsky Volcano and geometry of July 2012 field

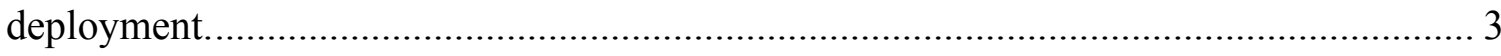

Figure 2. Schematic structure of a turbulent jet and noise source mechanisms. .............. 4

Figure 3. Axial distribution of relative noise source strength for a heated Mach 0.5

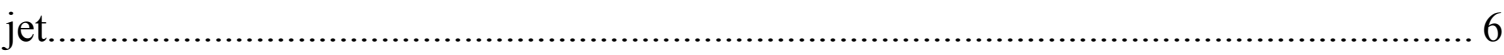

Figure 4. Photographs and waveforms illustrating the dominant activity observed

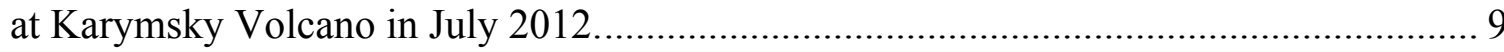

Figure 5. Schematic of space-time cone formed by a radially propagating sound-

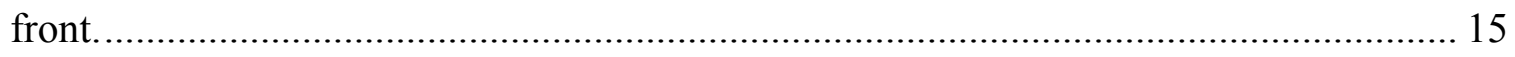

Figure 6. Synthetic network resolution test results demonstrating the vertical

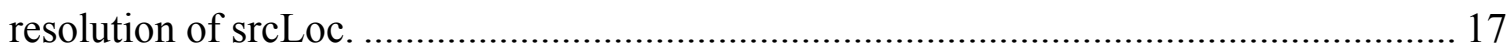

Figure 7. Acoustic source locations for explosion events at Karymsky. ......................... 22

Figure 8. Locations and correlation values for a srcLoc scan over $18 \mathrm{~h}$ of jetting

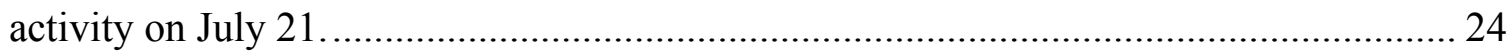

Figure 9. Comparison of 3D acoustic locations for the srcLoc and semblance methods. 25

Figure 10. Locations and correlation values for a semblance scan over $18 \mathrm{~h}$ of jetting activity on July 21, using a fixed sound speed of $340 \mathrm{~m} / \mathrm{s}$.

Figure 11. Evidence for strong influence on Karymsky explosion waveforms by crater/topography diffraction effects 



\section{Acknowledgments}

I, Colin Rowell, have authored this thesis in its entirety and completed the research contained herein. However, this research was completed with assistance from co-authors, who provided research funding, facilitated field research, and helped develop scientific concepts and discussion*. The first author and co-authors will be collectively referred to as "we" throughout this work. The following individuals are identified as co-authors:

\section{David Fee ${ }^{1,2}$, Curt A.L. Szuberla ${ }^{1}$, Ken Arnoult ${ }^{1}$, Robin Matoza ${ }^{3}$, Pavel P. Firstov ${ }^{4}$, Keehoon $\mathrm{Kim}^{5}$, Evgeniy Makhmudov ${ }^{4}$}

We thank the Institute of Volcanology and Seismology and the Kamchatka Branch of Geophysical Survey, Petravlovsk-Kamchatsky, Kamchatka, Russia, for hosting our field research. We thank Taryn Lopez, Dmitri Melnikov, Olga Khubaeva, Evgeniy Makarov, and Sergey Ushakov for their assistance with field and logistical support and DEM data.

This research was completed with support from the Geophysical Institute, University of Alaska Fairbanks. This research was funded via NSF grant EAR-1113294, and via the National Oceanic and Atmospheric Administration (NOAA) under Specific Cooperative Agreement NA08NWS4680044. The opinions expressed herein are those of the authors and do not necessarily reflect the views of the NOAA.

I would like to personally thank David Fee for the exceptional experiences and mentorship over the past two years. Thanks to my friends, new and old, and especially to those few with whom I will always be close, no matter the distance and time between us. Thank you, Kalina, for sticking with me this far. And thank you, Mom, Dad, Jared, and Kim for inspiring me to always pursue challenge, growth, and learning.

\footnotetext{
*This work is intended for submission and publication to the Journal of Volcanology and Geothermal Research. ${ }^{1}$ Wilson Infrasound Observatories, Geophysical Institute, University of Alaska Fairbanks, Fairbanks, AK, USA 



\section{Introduction}

Spatio-temporal source location of elastic waves is an important tool in acoustic and seismic studies of geophysical processes. We define an acoustic source as the region in space and time in which a physical process mechanically excites the ambient atmosphere, resulting in the propagation of acoustic waves. This may be the point and time at which a process first excites the atmosphere, or in the case of a distributed source, the region over which mechanical excitation occurs. In volcano studies, the reasons for locating acoustic sources are many: comparing the spatial relationships of acoustic and seismic sources in a volcanic system (Johnson, 2007), differentiating eruptive activity between different vents (Ripepe and Marchetti, 2002; Cannata et al., 2009), tracking of pyroclastic density currents (PDCs) (Ripepe et al., 2010), and long distance monitoring of remote volcanism (Matoza et al., 2011; Fee and Matoza, 2013). One of the challenges in locating acoustic sources from volcanoes is that most microphone deployments lie below the volcanic vent and are restricted to topography that is approximately two-dimensional (Matoza et al., in press). Such networks are severely restricted in their ability to resolve acoustic sources in the vertical dimension. To our knowledge, no 3-D volcano acoustic source localization studies have previously been undertaken.

Recent research has drawn links between the low-frequency acoustic signals from volcanic jets and the audible sound from man-made jet engines (jet noise), although this relationship has yet to be firmly established due to the complexities in volcanic jets and difficulty in making detailed observations (Woulff and McGetchin, 1976; Matoza et al., 2009a; Fee et al., 2010a; Fee et al., 2010b; Fee et al., 2013; Matoza et al., in press). A jet is defined as a sustained, momentum-driven, turbulent fluid flow issuing from a nozzle or vent. Jet noise is the acoustic radiation generated aerodynamically by turbulence within the jet flow itself. The acoustics of man-made jet engines are well characterized primarily due to development in the aeronautics industry (e.g. Tam, 1998; Tam et al., 2008; Viswanathan, 2009; Karabasov, 2010). Acoustic localization of man-made jet noise sources is typically done using arrays of microphones at a wide range of receiver angles or using directional and mirrored microphones. Turbulent jet flows have been observed to 
produce acoustic signals sourced along the edge of the jet, and experimental evidence suggests that turbulent noise sources peak at some distance downstream of the nozzle (Tam et al., 2006; Tam et al., 2008). If volcanic jets produce sound through similar mechanisms to man-made jets, it follows that sound sources in volcanic jets should be above (downstream of) the vent (Matoza et al., 2009a; Fee et al., 2013).

At Karymsky Volcano, Kamchatka, Russia, (Fig. 1a) the topography of an eroded edifice adjacent to the volcano, called Dvor Caldera, provides a platform for the deployment of a network of infrasound sensors in 3-D. Five infrasound microphones were deployed on this eroded edifice for 11 days in July 2012. Fig. 1b shows a satellite image of the two edifices, highlighting the caldera rims, 2012 campaign infrasound sensor locations, and field camp observation point, and Fig. 1c shows a photograph of Karymsky's summit region taken in September 2012. Fig. 1d shows a perspective view of a digital elevation model (DEM), showing the topography of the two edifices. The receiver sites were selected with the specific goal of achieving the maximum possible vertical relief across the network. Using signal processing and acoustic source localization techniques, this geometry also permits location resolution in the vertical axis, that is, in 3-D.

In this study we test and compare novel 3-D acoustic source localization techniques (Szuberla et al., 2009; Jones and Johnson, 2011). In Section 2, we first discuss some of the theory behind jet noise, particularly as it relates to noise source distribution within the jet. In Section 3 we describe the setting of Karymsky Volcano and outline the campaign deployment and the volcanic activity observed. In Section 4, we discuss acoustic source localization methods, and describe two approaches utilized in this study. We present the application of our chosen source localization methods to the Karymsky data set in Section 5. We conclude by comparing the results of each method, discuss the advantages and potential sources of error, and discuss potential future use of 3-D volcano acoustic source localization techniques. 

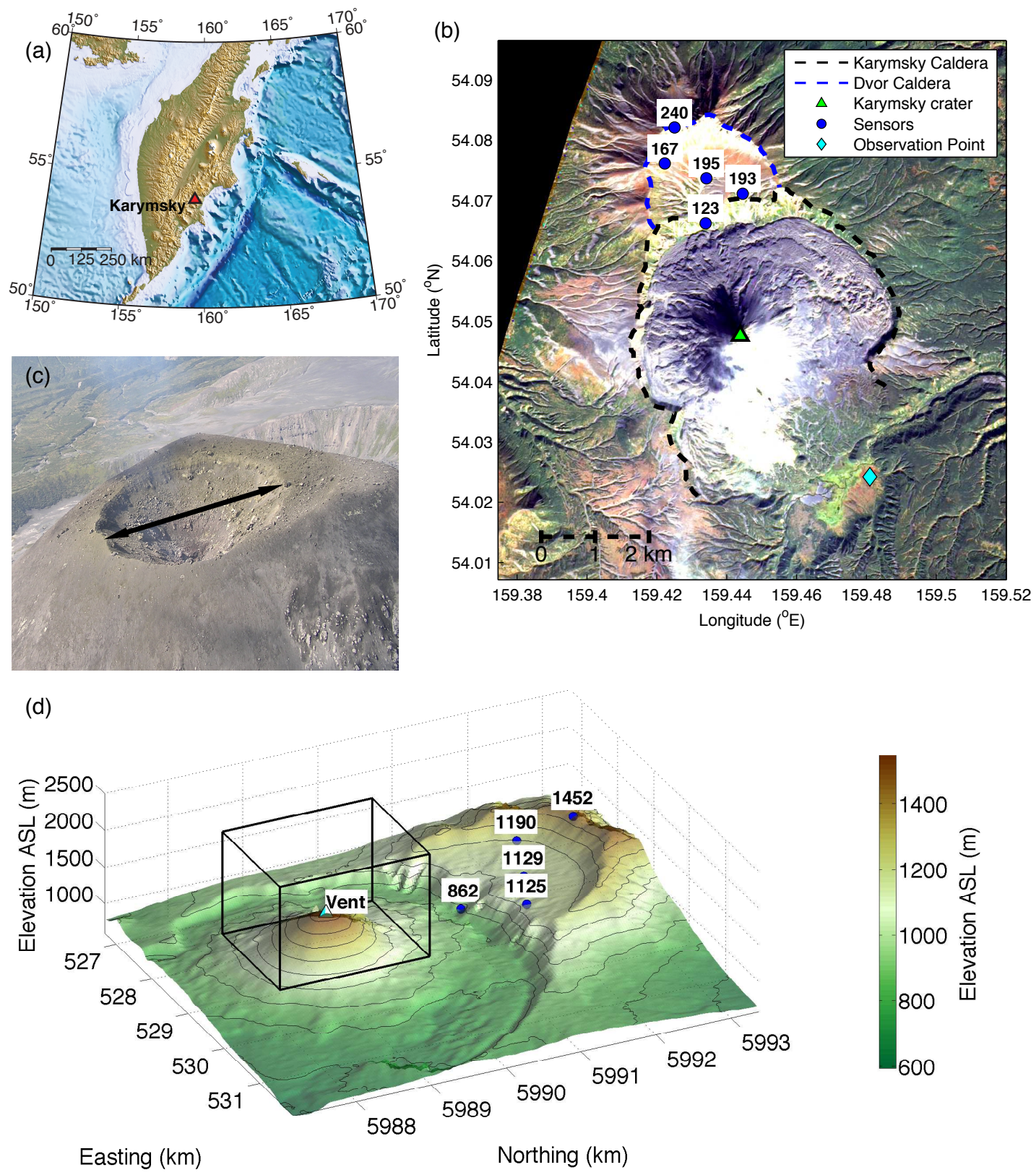

Figure 1. Location of Karymsky Volcano and geometry of July 2012 field deployment.

(a) Map of Kamchatka highlighting the location of Karymsky Volcano. (b) Satellite image of Karymsky Volcano. Acoustic sensor locations are labeled by sensor number. (c) Karymsky vent in September 2012. The crater diameter (black arrow) is estimated at $\sim 150 \mathrm{~m}$. Photo credit: Pavel Firstov. (d) DEM of the Karymsky and Dvor edifices. Sensor locations are labeled by elevation above sea level (ASL), in meters. The rectangular space about the Karymsky cone represents the grid space used for the semblance localization method discussed in Sections 4-5. 


\section{Jet Noise}

\subsection{Man-made jet noise}

Studies of man-made jets have recognized turbulence as a sound source for several decades (Lighthill, 1952; Lighthill, 1954; Tam, 1998). Fig. 2 shows a schematic diagram of jet structure and acoustic source regions. Modern aeroacoustic studies have shown that turbulent jet noise is composed of two dominant sources: (1) fine-scale turbulence (FST), and (2) large-scale turbulence (LST) (Tam et al., 1996). FST is thought to be generated by small (compared to the jet diameter), random eddies distributed throughout the jet while LST is generated by coherent turbulence structures, comparable in size to jet diameter, generated in the jet shear layer and propagating downstream. Jet noise is also highly directional. These two sound sources do not radiate isotropically, but are dominant at different observing angles to the jet axis (Fig. 2), with LST being strongest downstream in a cone about the jet axis, and FST dominating at other angles (Tam et al., 2008). The two sources can generally be identified with distinctive frequency spectra, which appear to be self-similar for both sub- and supersonic jets at a wide range of temperatures and jet diameters (Tam et al., 1996; Tam et al., 2008).

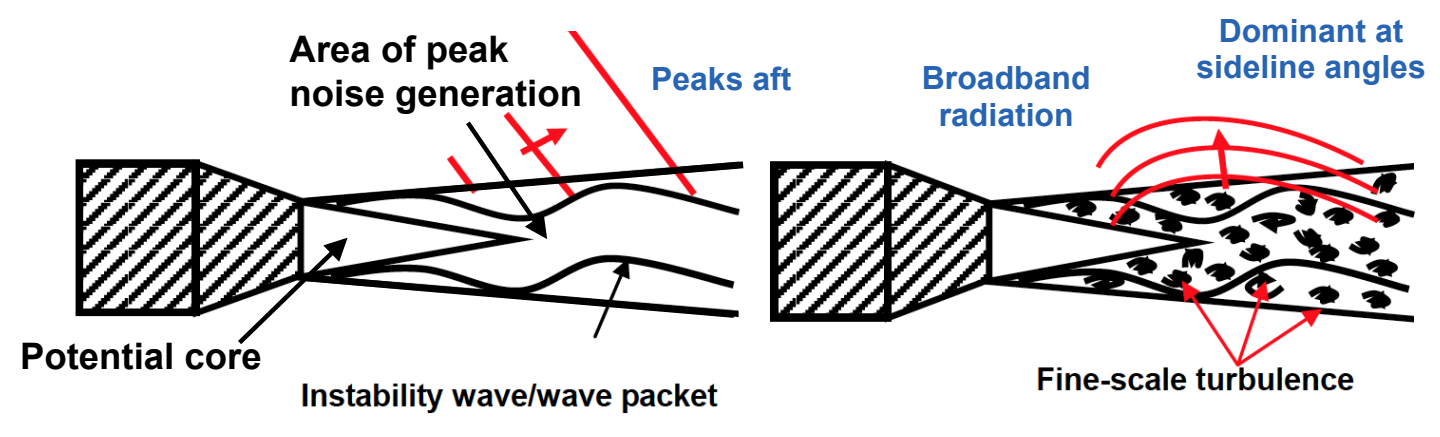

a) Large Scale Turbulence Noise

b) Fine Scale Turbulence Noise

Figure 2. Schematic structure of a turbulent jet and noise source mechanisms.

(a) Downstream propagation of large-scale, coherent instability waves produces the LST noise, radiating primarily in a cone about the jet axis. (b) Small-scale, random turbulence within the jet produces fluctuations in the ambient atmosphere, radiating sound primarily at angles perpendicular to the jet axis. Red lines indicate primary direction of sound radiation. Modified with permission from Schlinker et al. (2009). 
The interior of a jet flow contains a region of finite downstream length in which fluid velocity is nearly uniform, and little mixing occurs. This region is referred to as the potential core (Fig. 2a) (Gauntner et al., 1970; Crow and Champagne, 1971; Karabasov, 2010). Laboratory experiments using directional microphones indicate that the overall acoustic source power should peak near the end of the potential core, well downstream of the nozzle (Chu and Kaplan, 1976; Tam et al., 2006). Fig. 3 shows the measured overallsound pressure level (OASPL) against axial distance from the nozzle, normalized to units of jet diameter, for a Mach 0.5, heated jet (Tam et al., 2008). These data illustrate that the peak sound pressure occurs at a location several jet diameters downstream of the nozzle. The distance downstream of this peak source region increases considerably with jet velocity. Observing this phenomenon in volcanic jets is the primary motivation for this study.

\subsection{Volcanic jet-noise}

Volcanic eruption columns can be described as consisting of two primary regions: a momentum-driven gas-thrust region at the column base which transitions to a buoyant plume with altitude (Parfitt and Wilson, 2008). The gas-thrust region acts as a multiphase fluid jet injected from a vent into the ambient atmosphere. Woulff and McGetchin (1976) were among the first to suggest that acoustic signals from small-scale volcanic degassing were a form of low-frequency jet noise, and draw quantitative links between acoustic signals and volcanic eruptions. A variety of studies have applied their method to infer parameters of volcanic plumes (Vergniolle and Caplan-Auerbach, 2006; CaplanAuerbach et al., 2010; Ripepe et al., 2013). Understanding of jets and jet noise has now evolved and revealed additional complexity, but the concept of acoustic energy produced by turbulence within the jet remains central to jet noise theory (Matoza et al., in press). Recent infrasonic observations of volcanic eruptions have provided strong supporting evidence that a low-frequency form of turbulent jet noise can be a volcano infrasound source. Volcano acoustic signals with spectra resembling the LST similarity spectra have been observed for sustained eruptions at Mount St. Helens, Tungurahua Volcano, and Kasatochi Island (Matoza et al., 2009a; Fee et al., 2010a; Fee et al., 2010b). Fee et al. 
(2013) also observed a form of infrasonic "crackle" (Gee et al., 2007) from the 2011 eruption of Nabro Volcano, Eritrea. This unique acoustic signal is indicative of supersonic jet noise.

(a)

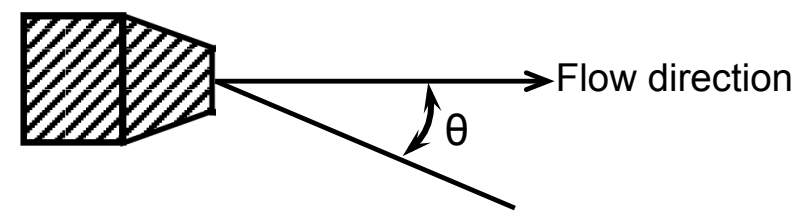

(b)

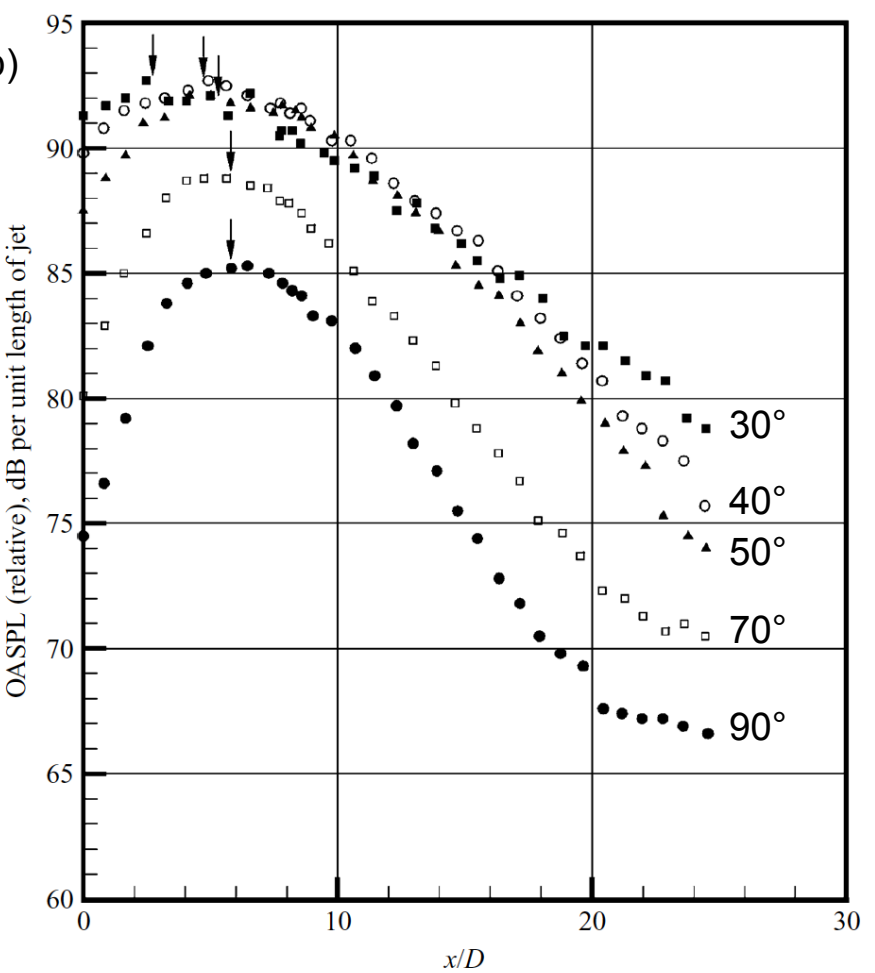

Figure 3. Axial distribution of relative noise source strength for a heated Mach 0.5 jet.

(a) The observation angle $\theta$ is defined where $\theta=0^{\circ}$ is parallel to the jet in the upstream direction. (b) Overall sound pressure level (OASPL) with normalized axial distance, $x / D$, where $x$ is the downstream distance from the nozzle, and $D$ is the jet diameter. Closed circles, $\theta=90^{\circ}$; Open squares, $\theta=70^{\circ}$; Triangles, $\theta=50^{\circ}$; Open circles, $\theta=40^{\circ}$; Closed squares, $\theta=30^{\circ}$. Arrows indicate locations of peak sound level. The apparent change in peak source region below $\sim 50^{\circ}$ is attributed to the change in dominant source from FST to LST. Modified with permission from Tam et al. (2008).

While these recent studies have provided tantalizing evidence of jet noise mechanisms at volcanoes, the extent of similarity between volcanic jets and man-made jets remains uncertain and quantitative links are still elusive. For illustrative purposes, we define the observation angle, $\theta$, as the polar angle to the jet axis, such that $\theta=0^{\circ}$ is parallel to the downstream direction of the jet (Fig. 3a). Since volcano acoustic field deployments are 
restricted to the ground surface, $\theta$ is generally greater than $90^{\circ}$ (Matoza et al., in press). At these angles in laboratory settings, the sound field is dominated by FST noise sources. Thus, jet noise theory predicts the frequency content of volcanic jetting signals recorded in the field to resemble FST similarity spectra; however, thus far the data show a better fit to LST spectra (Matoza et al., 2009a; Matoza et al., in press). This example is one of many illustrating that while jet noise may be prevalent from sustained eruptions, we are far from having a comprehensive model for volcanic jet noise. Another major problem in constraining volcanic jet noise is limited spatial or angular sampling of the acoustic wavefield. Studies of man-made jets typically involve laboratory settings in anechoic chambers (noise cancelling rooms) and relatively simple outdoor environments. Microphones are typically placed at multiple angles and distances to the jet axis. This has been essential for properly describing the directionality, distribution, and variety of jet noise sources (Tam et al., 2008). However, the restriction of volcano field deployments to topographic surfaces leads to a severe under-sampling of the acoustic wavefield from volcanic jets and contributes to large uncertainty in quantitative interpretation of signals (Matoza et al., in press). This uncertainty can be partially mitigated by deploying an infrasound network at a site with significant topographic relief. Maximizing elevation differences between sensors in proximity to a volcano can provide improved angular coverage relative to a vertical jet axis, and allow the discrimination of source processes in the vertical dimension. This would also facilitate improved detection

of events at varying source locations, such as from flank vents or fissure systems. Lastly, regular jet-like eruptions are necessary to test above-vent acoustic source location. Karymsky Volcano on the Kamchatka Peninsula, Russia, has both regular jetting eruptions and suitable topography, and is detailed in the next section.

\section{Campaign and Data}

\subsection{Karymsky Volcano}

Karymsky Volcano is an andesitic stratovolcano, and is one of the most active volcanoes on the Kamchatka Peninsula. It was constructed over the past 5300 years within the $\sim 5 \mathrm{~km}$ diameter Karymsky Caldera (Ivanov et al., 1991). The summit lies 
approximately $1550 \mathrm{~m}$ above sea level (ASL), while the active cone itself has a vertical relief of $\sim 800 \mathrm{~m}$. North and adjacent to Karymsky Caldera is an older edifice with a summit caldera, known as Dvor Caldera. At $\sim 1500 \mathrm{~m}$ ASL, the rim of Dvor Caldera is nearly as high as Karymsky cone itself (Fig. 1). The current eruptive episode began in 1996 with near simultaneous eruptions from both the summit vent and Karymsky Lake, $\sim 6 \mathrm{~km}$ south of the summit (Gordeev et al., 1997; Fischer et al., 2002; Izbekov et al., 2004). This eruption began with vigorous explosive activity and continuous ash emission, which declined to frequent, low-level explosive activity (Izbekov et al., 2004). This pattern of frequent, small explosions has persisted during the intervening period of 17 years. The explosions are typically discrete events characterized by ejection of ash and ballistics and are frequently followed by brief periods of audible degassing or jetting behavior (Johnson and Lees, 2000; Fischer et al., 2002). These events commonly produce plumes less than $1 \mathrm{~km}$ in height above the vent, though heights of $3 \mathrm{~km}$ or more do occur. The intermediate nature of these explosions has led to their description as transitional between Strombolian and Vulcanian-type (Johnson, 2007).

Since the current eruptive episode began at Karymsky, a number of geophysical studies have been carried out on the volcano. The first of these used combined seismoacoustic data to explain the processes driving the periodic explosions and degassing or “chugging" signals (Johnson et al., 1998; Johnson and Lees, 2000; Ozerov et al., 2003; Lees et al., 2004). Follow-up work was conducted to correlate observed eruptive velocities with acoustic and seismic amplitudes, in attempts to relate these quantities to eruption intensity, mass flux, and conduit geometry (Johnson, 2007). More recent work focused on the source processes generating shock waves during explosive events (Firstov et al., 2013). In each of these studies, specific reference is made to the eruptive events at Karymsky consisting of an initial, impulsive blast or explosion. In many cases, these events were followed by a period of continuous emission of a gas-ash mixture, lasting tens of seconds up to 10 minutes (Johnson and Lees, 2000; Firstov et al., 2013). Firstov et al. (2013) refer to this type of event as a "blow-through". Several of these events were observed during a field campaign in August 2011 (Lopez et al., 2013). Regular audible 
jetting and small ash explosions were punctuated by several larger explosive events. Explosive eruptions were preceded by periods of quiescence lasting $\sim 30$ minutes to 1 hour, with no visible emissions. The explosions themselves consisted of an initial impulse followed by a period of strong jetting. It is the jet-like behavior of these events that was of key interest for the present study.
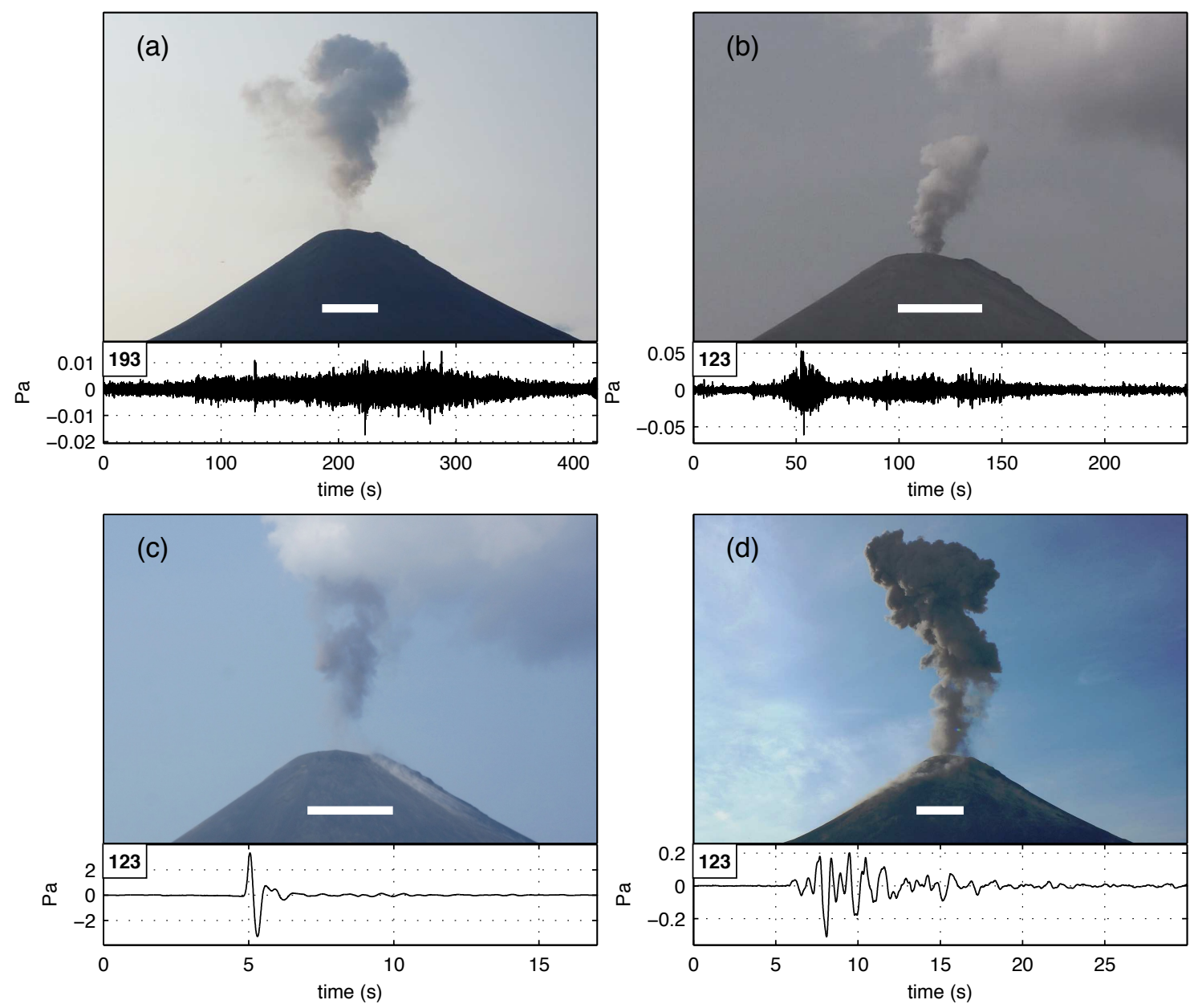

Figure 4. Photographs and waveforms illustrating the dominant activity observed at Karymsky Volcano in July 2012.

Waveforms are given variable bandpass filters based on signal content. (a) Jetting event at 07:10 July 18 . (b) Jetting event at 02:12 July 22. Images (a) and (b) are representative of degassing activity observed throughout most of the July 2012 deployment. Both of these signals are filtered between 10-40 Hz. (c) Small, ash-laden explosion at 01:17 July 22. This event is referred to as "explosion 1". (d) Ash-laden explosion at 07:09 July 25, referred to as "explosion 2". Both explosions are filtered between 0.2-20 Hz. Explosion 2 is less impulsive and has a smaller peak pressure than explosion 1, but produced a much larger ash plume. White bars in each photo indicate a scale length of $\sim 250 \mathrm{~m}$. Sensor number is listed in the top left corner of each waveform. 


\subsection{Acoustic data}

Dvor Caldera provides an excellent location for deployment of a 3-D acoustic sensor network. Five NCPA (National Center for Physical Acoustics) infrasound sensors were deployed on the Dvor edifice in July 2012, along with FLIR, video, and gas emission recordings at the observation site (Fig. 1b). Interpretation of source processes using the infrasound, FLIR, and gas emission observations are the subject of a separate study (Lopez et al., 2013). The acoustic network was deployed to maximize vertical relief between sensors, with an elevation difference of $590 \mathrm{~m}$ between the lowest and highest sensors. The recording sites are labeled with their elevation (ASL) in meters in Fig. 1d. The horizontal network aperture was $1.9 \mathrm{~km}$, and the closest and farthest sensors were 2.3 and $4.1 \mathrm{~km}$ from the vent, respectively. The NCPA sensors are compact, easily carried units, making them well suited for deployment in remote areas with limited access. Each sensor contains its own piezo-ceramic acoustic sensor, 24-bit digitizer, GPS antenna, wireless connection device, and disk storage, and requires only to be powered via a separate $12-\mathrm{V}$ battery. The sensors have a flat response between 0.02 and $250 \mathrm{~Hz}$, and a dynamic pressure range of $\pm 750 \mathrm{~Pa}$. The sensors recorded continuously for 10 days in July 2012 and are named with a three-digit number corresponding to their IP address (Fig. 1b). A sample rate of $250 \mathrm{~Hz}$ was chosen to capture signals in the infrasonic range, as well as higher frequency, audible events. All times are given in UTC.

Unfortunately, Karymsky was not as active during the 2012 campaign as in previous years (Lopez et al., 2013), with only small-scale jetting and degassing punctuated by occasional discrete ash explosions. Fig. 4 shows photographs and waveforms for examples of these events. The jetting events (Figs. $4 \mathrm{a}$ and $4 \mathrm{~b}$ ) were common throughout the campaign period, occurring more regularly and with greater signal amplitude during the first week. Waveforms are emergent, with individual episodes typically lasting a few minutes to a few tens of minutes. Frequency content for jetting signals ranged between 3 $\mathrm{Hz}$ up to at least the Nyquist frequency $(125 \mathrm{~Hz})$ in some cases, with typical peaks ranging from $15-25 \mathrm{~Hz}$. Jetting events were audible from the observation point and qualitatively reminiscent of a passenger jet engine, but the scale of jetting was relatively 
small with plumes generally rising $\sim 200-500 \mathrm{~m}$ above the vent. Only 3 small, discrete ash explosions were observed in daylight hours during the entire deployment (Figs. 4c and 4d). The two explosions examined here are each very different in character. Explosion 1 (Fig. 4c) was a highly impulsive, transient event, with the primary pulse lasting only $\sim 3 \mathrm{~s}$, followed by a low-amplitude coda of $\sim 10 \mathrm{~s}$. This explosion consisted of a single pulse of ash from the crater, accompanied by a few ballistic particles. Explosion 2 (Fig. 4d) was markedly different, consisting of a complex series of pulses lasting $\sim 12 \mathrm{~s}$, and more abundant ballistics. This event produced a much larger plume than explosion 1 , but at a much smaller peak acoustic pressure. The frequencies of both explosions peak in the 1-2 $\mathrm{Hz}$ range.

Due to the elevation and exposure of the highest sensors, wind noise was a significant problem in some periods of data collection. Of the three observed explosions, only the two described above have signal-to-noise ratios (SNR) sufficient to carry out source location processing. The larger explosions followed by sustained jetting witnessed in previous field campaigns did not occur during this deployment and the jets observed were of much smaller scale than those observed in previous volcanic jet noise studies (Matoza et al., 2009a; Fee et al., 2010a; Fee et al., 2013). Thus, high-velocity turbulent mixing noise was likely not present during our observation period. Nevertheless, the recorded signals were sufficient to provide test scenarios for the capabilities of the 3-D source localization techniques discussed herein. In particular, we test the performance limits of the location methods for signals of varying frequency, duration, and SNR. To visually compare source location results, a reference vent location was estimated using a combination of satellite imagery, DEM data, and photographs. No crater over-flight was possible during the field deployment, so the exact location and dimensions of the crater are uncertain due to the constantly evolving nature of the Karymsky crater (Firstov et al., 2013). Based on our observations, and observations from previous campaigns, the crater is estimated at 150-200 $\mathrm{m}$ in diameter; the error in reference vent location is estimated at $\pm 100 \mathrm{~m}$, or approximately the radius of the summit region. The vertical coordinate of the vent was taken from the DEM data, and is subject to some uncertainty due the relatively 
low resolution of the DEM $(\sim 18 \times 30 \mathrm{~m}$ per pixel). Fig. 1c shows a photograph of the crater taken in September 2012. Based on this image, the crater depth is estimated at $\sim 50$ $75 \mathrm{~m}$.

\section{Localization methods}

\subsection{Localization primer}

Multi-channel acoustic data can be used to estimate source locations through a variety of different approaches. Acoustic source localization methods are generally divided into three different stratagems: (1) back-azimuth or beamforming, (2) high-resolution spectral estimation, or (3) utilization of time-difference-of-arrival (TDOA) information (DiBiase et al., 2001). Beamforming typically involves phase aligning multichannel data by applying time shifts to individual channels, then summing the signals. The phase-aligned signals will "stack" constructively with improved SNR, assuming an incoherent noise field (Olson and Szuberla, 2009). The time delays are determined by searching over back-azimuth and sound speed or spatial location and sound speed, for the cases of far-

field plane waves or local spherical waves, respectively (DiBiase et al., 2001; Olson and Szuberla, 2009; Thomas, 2009). In the case of infrasound studies, traditional location techniques, particularly at ranges greater than about $10 \mathrm{~km}$, utilize beamformed backazimuth information from multiple sensor arrays to triangulate the source region (Olson and Szuberla, 2009; Matoza et al., 2011). Spectral estimation techniques employ a wide range of approaches, but generally involve deconvolution of coherent signal and noise in the frequency domain (Johnson and Dudgeon, 1993; DiBiase et al., 2001). Such techniques are not commonly applied in infrasound studies, but have been utilized for man-made jet noise studies (Papamoschou, 2011). As the name implies, TDOA methods first estimate the relative difference in arrival times between station pairs, and use this information to formulate an inversion for source parameters.

In volcano acoustics, source location techniques typically divide into back-azimuth beamforming (Garcés et al., 2003; Matoza et al., 2011) or grid-search methods. Shortrange volcano acoustic studies (i.e. within about $5-10 \mathrm{~km}$ ) have generally utilized grid- 
search procedures, in which the source location is assumed to emanate from the grid node that minimizes an error function (Johnson et al., 2003; Jones et al., 2008) or maximizes coherency (Ripepe and Marchetti, 2002; Montalto et al., 2010). For the present work, an inverse, TDOA-based locator is compared against a forward, grid-search-based technique. Wilson Infrasound Observatories developed a time-difference-of-arrival localization algorithm, termed the "UAF Source Locator" (Szuberla et al., 2009; Arnoult et al., 2010), referred to herein as "srcLoc". This technique was developed to locate acoustic sources in 2- and 3-D, but has only been extensively tested in 2-D. Thus, the data set and sensor geometry at Karymsky represent a good opportunity to test the limits of the locator in 3-D for signals of varying frequency, duration, and SNR. The second method uses a grid-search to calculate the source location by determining the node in grid space with maximum semblance coefficient. Semblance-based source localization methods have been employed in a variety of situations for both seismic and acoustic applications at volcanoes (e.g. Ripepe and Marchetti, 2002; Almendros and Chouet, 2003; Dawson et al., 2004; Jones and Johnson, 2011; Cannata et al., 2011).

\subsection{Inverse locator: srcLoc}

The srcLoc algorithm is a two-stage acoustic source locator designed as a rapid and accurate alternative to traditional triangulation methods in the near-field (Szuberla et al., 2009; Szuberla and Arnoult, 2011). The locator uses input in the form of spatial locations of the microphones and a vector of time lags for each unique sensor pair. The time lags are typically determined via cross-correlation between channels. The first stage of the locator uses sensor locations and TDOA information to perform a least-squares inversion for source location. It is, in this respect, very similar to modern least-squares earthquake localization methods. srcLoc differs, however, in that it uses a novel approach to calculating an analytic solution for the source location and sound speed. For illustrative purposes, we first discuss the case of flat topography, in which the sound source and sensors can all be considered fixed on a horizontal ground surface. Thus, the source location problem reduces to determining two spatial dimensions, and one temporal dimension. The sensors, while stationary in space, can be considered to move linearly 
forward in time. A sound wave generated at a compact source with constant sound speed propagates radially in space, and its radius increases linearly in time. Assuming an isotropic and homogeneous atmosphere (effectively assuming no wind or temperature variations), this propagation pattern traces out a 3-D, right, circular "space-time cone", as illustrated in Fig. 5. The intersection of the cone with the sensor "world lines" gives the arrival time information at each sensor. Thus, the locator inverts for the 3-D cone that best fits arrival time information. The vertex of the best-fit cone gives the source location in space, $x_{s}, y_{s}$, and time, $t_{s}$, while the slope of the cone is inversely proportional to the sound speed, $c$. In the case where topography is significant and a third spatial dimension, $z_{s}$, must be included, the equation takes on the form of a 4-D "hypercone":

$$
\left(x_{i}-x_{s}\right)^{2}+\left(y_{i}-y_{s}\right)^{2}+\left(z_{i}-z_{s}\right)^{2}=c^{2}\left(t_{i}-t_{s}\right)^{2}
$$

The spatial coordinates of the $i$ th sensor are given by $x_{i}, y_{i}, z_{i}$, and the signal arrival time at the $i$ th sensor by $t_{i}$. Considering Eq. (4.1) for a second sensor with space-time coordinates, $x_{j}, y_{j}, z_{j}, t_{j}$, the second cone equation can be subtracted from the first to express the solution as a function of space and time differences between sensors:

$$
\begin{gathered}
{\left[-2\left(x_{i}-x_{j}\right)\right] x_{s}+\left[-2\left(y_{i}-y_{j}\right)\right] y_{s}+\left[-2\left(z_{i}-z_{j}\right)\right] x_{s}+\left[2 c^{2}\left(t_{i}-t_{j}\right)\right] t_{s}} \\
=-\left[x_{i}^{2}-x_{j}^{2}\right]-\left[y_{i}^{2}-y_{j}^{2}\right]-\left[z_{i}^{2}-z_{j}^{2}\right]+c^{2}\left[t_{i}^{2}-t_{j}^{2}\right]
\end{gathered}
$$

Eq. (4.2) is now linear in $x_{s}, y_{s}, z_{s}$, and $t_{s}$, and is used to formulate the least-squares solution for each sensor pair. The analytic solution to the least squares problem is nonunique and takes the form of a cubic equation in $c$, for cases in both two and three spatial dimensions. Thus up to three mathematical solutions are possible. In most cases, two of these solutions are complex and can be discarded as non-physical. The second stage of the algorithm uses the analytic solutions as a seed for a Nelder-Mead numerical optimization routine (see Press et al., 1992). The optimization searches local space about the analytic solutions, selecting a single final solution via a minimized cost function. The resulting algorithm has been optimized for high efficiency, with the actual determination of time lags via cross-correlation being the most computationally expensive component 
(Szuberla et al., 2006). In addition to its rapid calculation, srcLoc has been shown to provide an order of magnitude or more improvement in accuracy over near-field backazimuth techniques for localization in two dimensions (Szuberla et al., 2009).

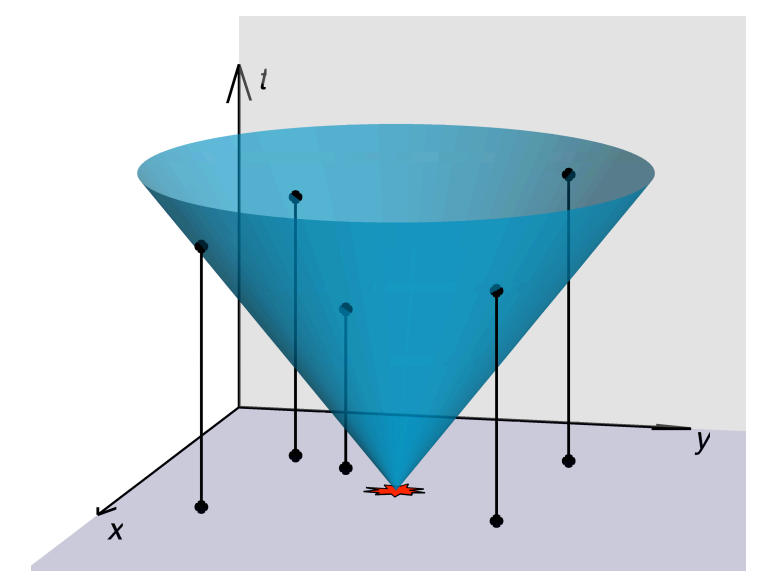

Figure 5. Schematic of space-time cone formed by a radially propagating sound-front.

This example illustrates the two-dimensional case of flat topography. The intersection of the sound cone with sensor timelines gives arrival time information. The srcLoc procedure inverts the arrival times to determine the cone vertex. In three spatial dimensions, the wavefront takes the form of a four-dimensional hypercone. Modified with permission from Szuberla and Arnoult (2011).

Implicit in the calculations of the analytic solutions are several key assumptions. As stated previously, the fit of propagation pattern to the shape of a cone requires a homogeneous, isotropic, and windless atmosphere. This is, of course, not the case in reality, and studies have shown that propagation effects can be significant over relatively short distances (Fee and Garcés, 2007; Matoza et al., 2009b; Johnson et al., 2012). However, since the sensors are all within $\sim 4 \mathrm{~km}$ of the vent, this provides a reasonable first approximation (Fee and Matoza, 2013). A second assumption is that the source is compact and spatially stationary. As discussed in Section 5.2, these assumptions are not necessarily viable for the purpose of studying volcanic jets. Jet noise is inherently a distributed source, as sound is produced along the axial length of the jet (Fig. 2) (Papamoschou, 2011). Thus, the assumption of compactness may not always be valid, especially for large-scale volcanic jets in Vulcanian or Plinian columns. Furthermore, the jet is by nature composed of turbulence components propagating downstream at high velocity, particularly in the case of LST structures. Over long time scales, a stationary 
source assumption is likely not valid, though it may be sufficient for short time scales. We address the validity of these assumptions in greater detail in Section 5.3.

A minimum of five sensors is required to locate acoustic sources in 3-D using srcLoc. Thus, without additional channels to constrain arrival times, it was necessary to assess the resolution of srcLoc for the Karymsky network geometry. We perform resolution tests using a forward model approach to assess the uncertainties of 3-D source locations. Using a reference source location (i.e. Karymsky summit or a hypothetical jet source some distance above the vent), acoustic velocity, and infrasound sensor locations, a vector of theoretical cross-correlation lags is calculated. A synthetic signal is then produced; in this case a broadband explosion pulse with an exponentially decaying coda at peak frequency of $2 \mathrm{~Hz}$. The synthetic signal is replicated for each channel, and then shifted in time using the calculated cross-correlation lags. Gaussian random noise is added to each channel according to an appropriate SNR, based on real signals recorded at Karymsky. This synthetic set of noisy data is passed into a cross-correlation routine to determine a time lag vector, $\tau$, where the elements of the vector are the arrival time differences between each unique sensor pair. These steps are repeated 1000 times to produce an array of $\tau$ vectors. The mean (or bias) and standard deviation of these vectors are calculated. These quantities give a statistical measure of the expected error associated with a given sourcereceiver geometry. Statistical parameters are then used to synthesize separate sets of randomized $\tau$ vectors, which are then passed into srcLoc to evaluate the range in errors in each of the spatial dimensions. The results of these tests at a range of SNR and jet heights are shown in Fig. 6. For SNR $\sim 1(0 \mathrm{~dB})$ in the frequency pass band, srcLoc still has a resolution of approximately \pm 150 meters in the vertical domain, to a 95 percent confidence. For higher SNR $\sim 3.2(10 \mathrm{~dB})$, the resolution becomes $\pm 50 \mathrm{~m}$. Coherent signals from Karymsky for this data set generally have SNR well above 1 in their peak frequency range. Excluding errors from strong propagation affects, source directionality, or non-random noise, these simulations demonstrate that the locator is capable of resolving sources in the vertical dimension with a high degree of accuracy for the Karymsky network geometry. 


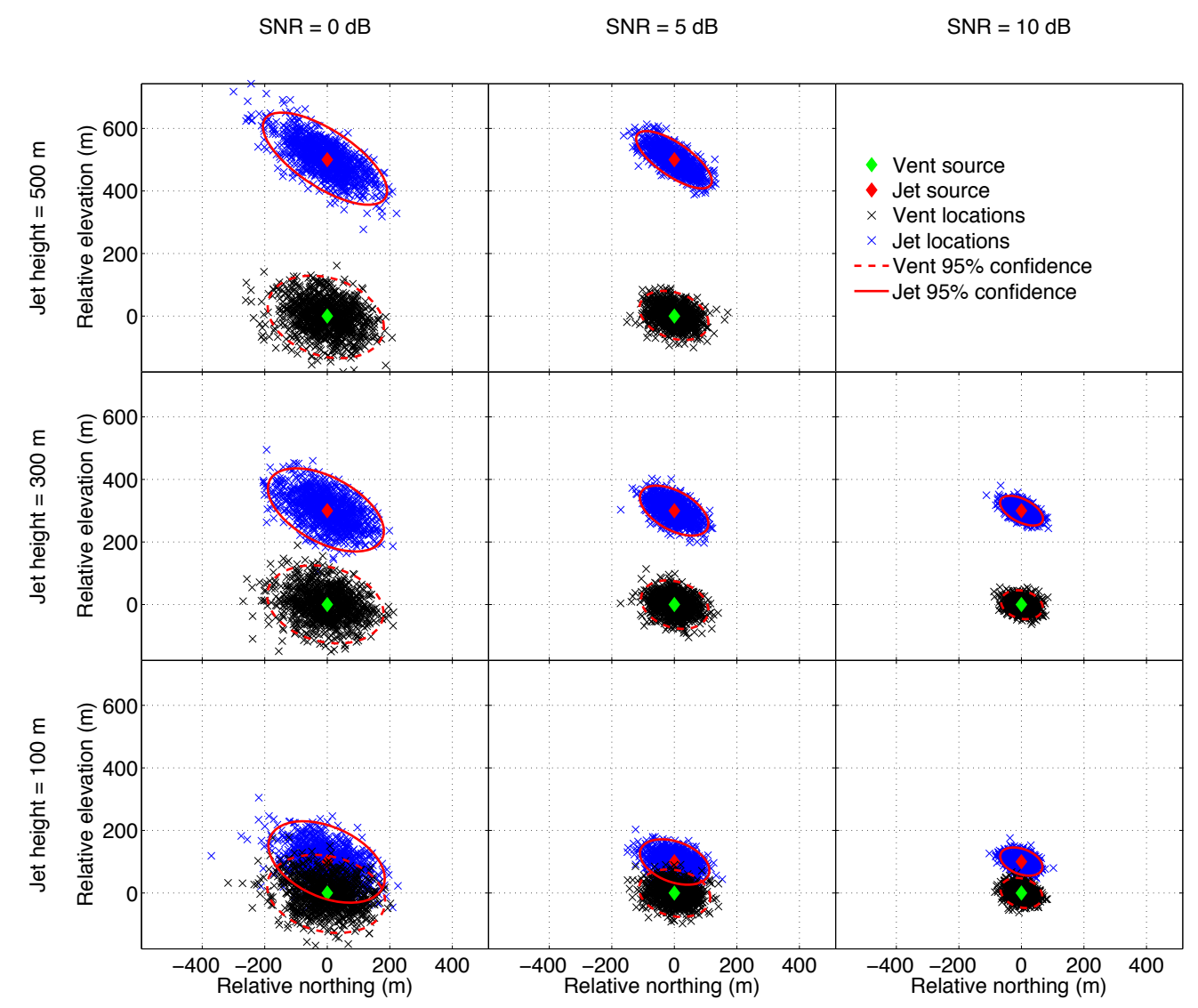

Figure 6. Synthetic network resolution test results demonstrating the vertical resolution of srcLoc. Each panel shows location distributions for a given signal-to-noise-ratio (SNR) and jet source height. For each case, 1000 trials are run for each of the two sources (vent vs. jet), and are plotted in two dimensions with Northing and elevation relative to the vent. 95\% confidence ellipses (red) show that even for low signal levels at $0 \mathrm{~dB}(\mathrm{SNR}=1)$, differences of 200 to $300 \mathrm{~m}$ can be resolved. The sensor network is located in the positive direction on the horizontal axis. The errors in the east-west dimension are not shown, as they are considerably smaller than in the other two dimensions.

To determine the optimal filter to produce maximum coherence and stable source locations, test locations were calculated for data filtered at a variety of frequency bands, and it was found that choice of filter had a noticeable effect on source location. Horizontal locations varied by no more than about $10 \mathrm{~m}$. Vertically, however, the effect was much more significant, with scatter of up to $100 \mathrm{~m}$, and was most heavily influenced by the choice of the bandpass lower limit. The vertical scatter of explosion locations was generally found to be smallest $(<50 \mathrm{~m}$ ) for a lower frequency limit of $0.2 \mathrm{~Hz}$. Thus, for the explosion data and results presented herein, explosion waveforms were bandpassed 
from $0.2-20 \mathrm{~Hz}$. A similar analysis was performed for the jetting events. In general, a broad filter of 10 to $40 \mathrm{~Hz}$ was used to locate these events. This band was found to produce the best signal coherency for the high frequency events. At frequencies lower than $5 \mathrm{~Hz}$, SNR drops below 1 rendering signals largely incoherent. Correlation between sensors degrades further at higher frequencies.

Given the large quantity of data with regard to the jetting activity, it was practical to develop scanning routines for both location methods, utilizing a sliding window over which to record a variety of parameters. A variety of windows were tested, but in general a 30 s window with $50 \%$ overlap was found to give good correlation and was capable of capturing time-varying trends. Due to the optimized efficiency of the srcLoc program, this scanning can be done much faster than real-time, such that scanning over a full day of data can be done in only a few minutes on a standard desktop computer.

\subsection{Forward locator: semblance}

Semblance is a coherence measure mathematically related to cross-correlation, and was first introduced by Neidell and Taner (1971). In the context of grid-search geophysical source localization, semblance is considered a proxy for the likelihood that an acoustic or seismic source originates at a given grid-node (Montalto et al., 2010; Cannata et al., 2011). For signal window $N$ samples long recorded on $M$ channels, the dimensionless, amplitude-normalized semblance coefficient is given by

$$
\begin{gathered}
S=\frac{1}{N M^{2}} \sum_{n=1}^{N}\left(\sum_{m=1}^{M} \frac{A_{m}\left(\tau_{m}+n d t\right)}{\sigma_{m}}\right)^{2} \\
\sigma_{m}=\sqrt{\frac{1}{N} \sum_{n=1}^{N} A_{m}\left(\tau_{m}+n d t\right)^{2}}
\end{gathered}
$$

where $A_{m}$ is the amplitude information for the $m$ th channel, $\tau_{m}$ is the start time of the window, and $\sigma_{m}$ is the root mean square (RMS) amplitude over the time window for the $m$ th channel. The normalization via $\sigma_{m}$ is necessary to remove the influence of amplitude variations across the network and only assess waveform similarity. The relative time lag, 
$d t$, is the calculated difference in travel time from the current grid node relative to that of a reference sensor. That is, $d t=\left(t_{m}-t_{r e f}\right)$, where $t_{m}$ is the calculated sound travel time to the $m$ th sensor, and $t_{r e f}$ is the calculated travel time to the reference sensor. For Karymsky data, sensor 123 was used as the reference sensor (Fig. 1). Travel times were calculated assuming a fixed and constant sound speed, $c$, as $t=r / c$, where $r$ is the slant distance from grid-node to receiver.

Almendros and Chouet (2003) show that Eq. (4.3) can be expressed in terms of an average of the cross-correlation coefficients for all possible $\left(M^{2}\right)$ channel pairs:

$$
S=\frac{1}{N M^{2}} \sum_{n=1}^{N}\left(\sum_{m=1}^{M} \frac{A_{m}\left(\tau_{m}+n d t\right)}{\sigma_{m}}\right)^{2}=\frac{1}{M^{2}} \sum_{m, o=1}^{M} \frac{C_{m o}}{\sqrt{C_{m m} C_{o o}}}
$$

Almendros and Chouet (2003) combine all channels into the calculation of a single semblance map. Jones and Johnson (2011) adapted this method for infrasound applications, in which they employed a slightly different approach. They applied the semblance equation to only two channels at a time, repeating this step for all unique sensor pairs, where the number of pairs, $p$, is given by the binomial coefficient, $p={ }_{m} C_{2}$. This leads to an output of $p$ separate semblance maps. The individual maps are then multiplied together, producing a final map of "stacked" or "exponential semblance", $S_{e}$. This has the effect of reducing side lobes and emphasizing the location of maximum semblance, $S_{m}$, which is assumed to represent the source location (Jones and Johnson, 2011). The method presented here is a combination of the cross-correlation relation (Eq. (4.5)) and 3-D grid of Almendros and Chouet (2003), with the pair-wise semblance map calculation of Jones and Johnson (2011). Using this formulation, the right side of Eq. (4.5) gives a semblance value of 0.5 for uncorrelated white noise, while a value of 1 indicates perfect coherency. Stacked semblance values for five sensors $(p=10)$ vary between corresponding values of $S_{e}=0.5^{10}=9.77 \times 10^{-4}$ and $1^{10}=1$, respectively, on an exponential curve. 
To determine source location using semblance, a grid space is first defined containing the region where sources are expected to occur. The grid used here is centered horizontally about the Karymsky summit, with easting, northing, and vertical dimensions of 1.6, 2.0, and $1.4 \mathrm{~km}$, respectively. Fig. 1d shows the geometry of the semblance grid superimposed on the Karymsky DEM. Since signal coherency over a given distance is dependent on frequency content, grid-node spacing was varied to locate signals of different peak frequency. Node spacing less than the peak acoustic wavelength is necessary for accurate resolution. For explosion events, with peak frequencies of 1-2 Hz (wavelengths of $340-170 \mathrm{~m}$, respectively), a grid-node spacing of $50 \mathrm{~m}$ was sufficient to provide robust source locations, though $20 \mathrm{~m}$ was generally used for improved resolution. For the higher-frequency jetting signals, with peak frequencies of $\sim 15-25 \mathrm{~Hz}$ (wavelengths of $\sim 23-17 \mathrm{~m}$ ), a grid spacing of $10 \mathrm{~m}$ was used to accurately resolve sources. Smaller grid spacing was inhibited by computational cost.

Travel times from each grid-node to each receiver are then computed and used to determine the appropriate cross-correlation lags for each grid node, which were then applied using Eq. (4.5) for each sensor pair. The resulting total of $p$ semblance-pair maps are multiplied together to produce the final stacked-semblance map. To analyze the timevariant locations of jetting signals, this procedure is applied with a sliding window over the signal, with windows typically $30 \mathrm{~s}$ in length and overlapping by $50 \%$. It was found that for shorter window lengths, correlation values drop quickly. This can likely be attributed to overall low coherency of the high-frequency jetting signals across the scale of the network, so capturing longer segments of signal helps to average out loss of coherency due to noise. Windows of $30 \mathrm{~s}$ allow for good correlation values, while still capturing time variance in jetting events.

\section{Results and discussion}

\section{$5.1 \quad \operatorname{srcLoc}$}

The srcLoc algorithm is first used to locate sources for the discrete ash explosions. The first event examined was explosion 2 (Fig. 4d). Figs. 7a and $7 \mathrm{~b}$ show the source 
location determined for this event (blue triangle). While this event was only about $20 \mathrm{~s}$ in length, it produced the more complex signal of the two explosions, and was hypothesized to result from a more distributed or evolving source location than explosion 1. Locations were determined for this event using both the complete waveform and a sliding window capturing a couple cycles. For both windowed locations and using the complete waveform, however, locations agree for a source within $100 \mathrm{~m}$ of the reference vent location. This provides evidence for a high degree of accuracy in the srcLoc algorithm. Explosion 1 (Fig. 4c) has a short duration $(\sim 3 \mathrm{~s})$ and its source location differs significantly from that of explosion 2. This output location is fully $500 \mathrm{~m}$ above the reference vent, as shown in Figs $7 \mathrm{a}$ and $7 \mathrm{~b}$ (red triangle). This strong divergence between the two explosion locations is unexpected, and is not easily explained by obvious noise sources. Fig. 7c shows the same photograph of explosion 1 as Fig. 4c, with the region approximately 500 meters above the vent highlighted. The short duration of this event would not allow a well-defined, extended jet to develop, and a sound source is not expected at this altitude. It is instructive to compare the sound speed, $c$, for these events as determined by the locator. Given typical summertime temperatures at Karymsky, we expect sound propagation speeds to range between $335-345 \mathrm{~m} / \mathrm{s}$. For explosion 2, $c$ is determined to be $336 \mathrm{~m} / \mathrm{s}$, giving added confidence to the location accuracy. For explosion 1, however, $c$ is calculated as $316 \mathrm{~m} / \mathrm{s}$. This is unreasonably low, as it requires atmospheric temperatures below $-20^{\circ} \mathrm{C}$. While it is possible for winds to strongly alter effective sounds speed (Fee et al., 2010b), no strong winds were observed during this period, as evidenced by lack of drift in the visible plume and low noise in the acoustic channels. This observation indicates that the large apparent error in source location for explosion 1 is correlated with an apparent error in sound speed, although a physical explanation remains elusive. We discuss these unusual discrepancies in greater detail in Section 5.3. 

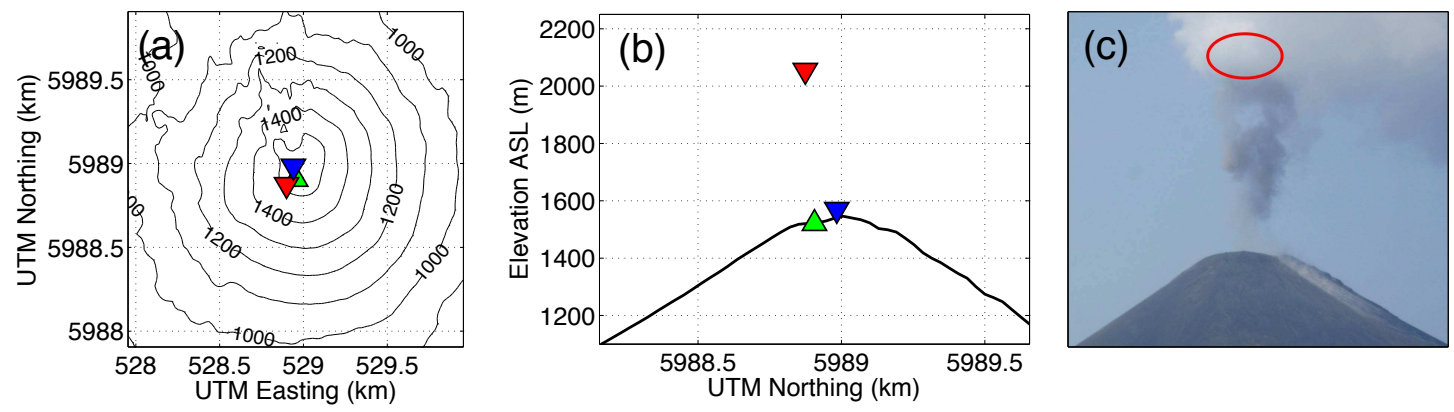

Figure 7. Acoustic source locations for explosion events at Karymsky.

(a) Contour map of the Karymsky cone, showing the locations in horizontal space. The upward-pointing, green triangle is the estimated vent location. Explosions 1 and 2 are represented by the downward-pointing red and blue triangles, respectively. (b) Vertical locations shown on a profile of Karymsky, as viewed from due east, showing the pronounced elevation of the location for explosion 1. (c) Photo of explosion 1 from the observation point. The red circle highlights the approximate region of the calculated source location from srcLoc, $\sim 500 \mathrm{~m}$ above the vent.

High-frequency jetting signals are also located. If these events produce jet noise in a similar manner to those of man-made jets, it is useful to consider where we might expect the peak noise source to occur. Estimates from remote sensing data place the width of the Karymsky summit region, as viewed from the observation post, at $228 \pm 5.7 \mathrm{~m}$ (Lopez et al., 2013). Using this as a benchmark, we estimate the expanded jet diameter for several episodes of jetting activity. With this approach, a typical jet diameter is about $50 \mathrm{~m}$.

Considering the data displayed in Fig. 3 for a jet velocity of Mach $0.5(\sim 170 \mathrm{~m} / \mathrm{s})$ and assuming a similar relationship at volcanic scales, we might expect the peak sound source to occur at $x / D \approx 6$ or $300 \mathrm{~m}$ above the vent. However, the gas velocities observed at Karymsky are considerably less than Mach 0.5, as Lopez et al. (2013) give average ascent velocities on the order of $10 \mathrm{~m} / \mathrm{s}$. At such low velocities, the peak sound region might lie at an $x / D$ of no more than 1-2 ( 50-100 m). Additionally, the true jet nozzle likely occurs at some depth within the crater. Thus, we expect that this particular jet noise source during our deployment would occur within $\sim 50 \mathrm{~m}$ of the crater rim, which is unresolvable considering our network geometry (Section 4.2). The source locations for the jetting events are thus expected to be similar to explosion 2: in a cluster centered on the volcano summit. 
As discussed in Section 4.2, a window scan routine was used to locate jetting signals. The srcLoc scanner was run over most of the data set. Some time periods were excluded in which one or more channels were too saturated with wind noise to provide viable locations, as determined by visual inspection of waveforms and/or test locations. Fig. 8 shows the results of a scan over $18 \mathrm{~h}$ of data on $21 \mathrm{July}$, with the vertical source location difference from the reference vent plotted against the averaged cross-correlation value for each window in Fig. 8a. We consider this vertical distance to represent the primary source location error. Two trends are immediately evident: 1) the wide range of elevations for windows with cross-correlation values below $\sim 0.45$ and 2 ) the distinct clustering of events above the vent. Over $46 \%$ of all locations for this scan occur in a region between 165 and $720 \mathrm{~m}$ above the vent, for all values of cross-correlation above $\sim 0.2$. While these cross-correlation values are low compared to the standards of most acoustic studies, we expect relatively low coherency for the jetting signals, as their peak wavelength $(\sim 20 \mathrm{~m})$ is only about $1 \%$ of the network aperture $(\sim 2 \mathrm{~km})$. Despite low correlation values, the clustering of events in space is taken as evidence of coherent signals. Nearly all of the clustered events are within a $200 \mathrm{~m}$ horizontal radius from the vent. The vertical axis is limited here to $\pm 3 \mathrm{~km}$, but ranges extend out to near infinity for many source locations. Sources located at extreme range typically indicate that the locator cannot find a viable solution for the hypercone equation, and are indicative of incoherent waveforms. These errant locations do not occur above correlation values of $\sim 0.45$, thus this value is used as a "detection" threshold for our analysis. Only source locations exceeding this minimum correlation threshold are shown in Figs. 8b and 8c and used for further analysis. Fig. $8 \mathrm{~b}$ shows the source locations in map view, superimposed on a contour map of Karymsky. As expected from the synthetic tests covered in Section 4, the errors are small in the east-west direction, as the sensor network has the greatest coverage in this dimension with respect to the vent. Similarly, larger errors occur in the north-south directions, i.e. parallel to the viewing angle of the network, again in agreement with simulations. Fig. 8c shows the same cluster of events, superimposed on a DEM surface, as viewed from due east. This clearly illustrates the distinct clustering of 
locations directly above the vent. As was the case for explosion 1, these locations appear unrealistically high compared to the scale of the jet and plume. Examination of data from other time periods reveals that this apparent elevated source region occurs consistently throughout the campaign period, for a wide range of atmospheric wind and temperature conditions. In the next section we compare semblance locations to these unexpected results.
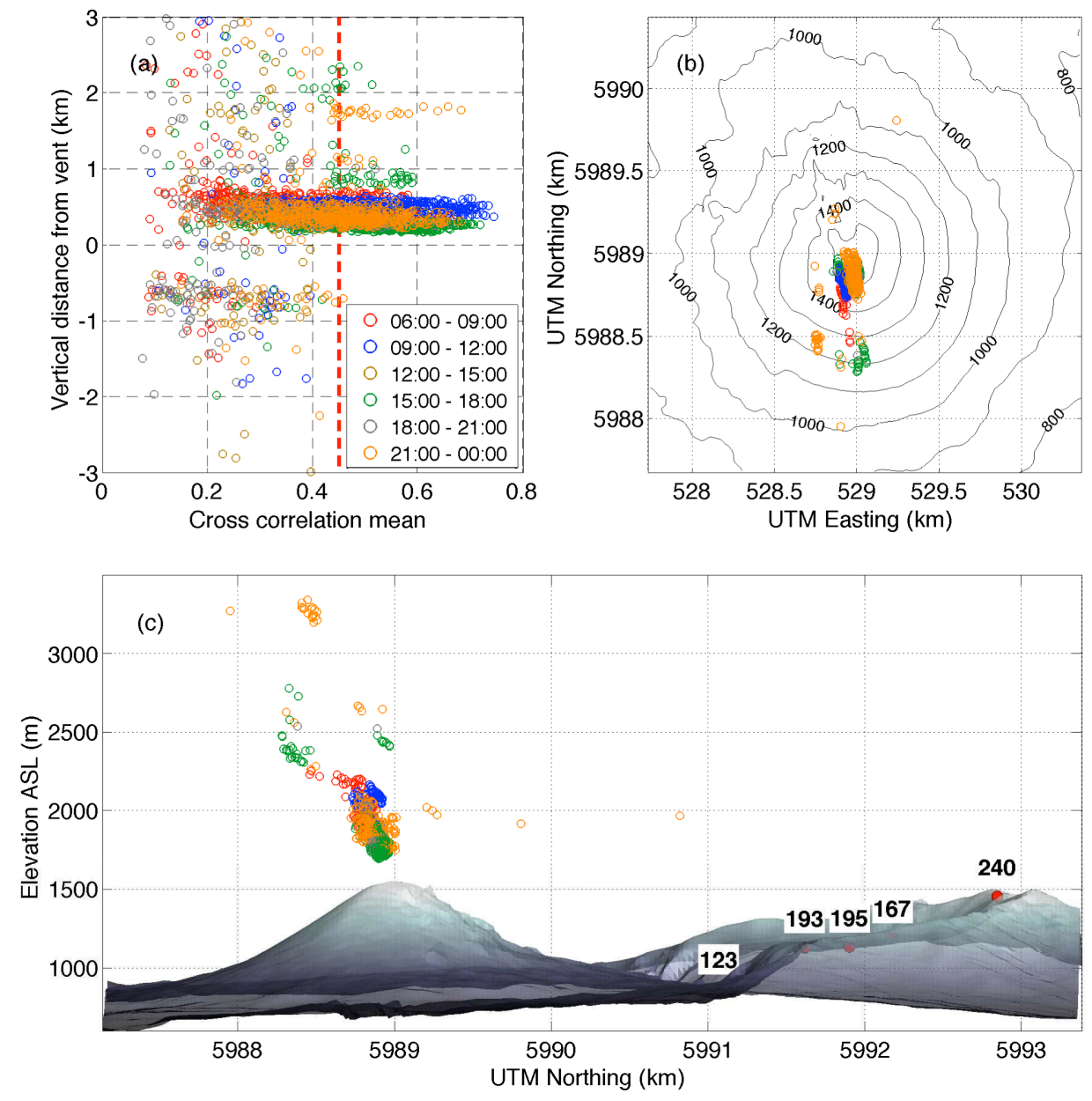

Figure 8. Locations and correlation values for a srcLoc scan over $18 \mathrm{~h}$ of jetting activity on July 21 . (a) Cross-correlation versus vertical distance from vent, where 0 on the $y$-axis corresponds to the reference vent elevation. Below a correlation value of $\sim 0.45$, events scatter widely in elevation, and collapse to only a few tight clusters above this value. The largest cluster, between $\sim 200-700 \mathrm{~m}$ above the vent, contains over $46 \%$ of all recorded locations for this time period, regardless of correlation value. (b) Map view of Karymsky, showing locations with correlation values above 0.45 . The main cluster occurs in tight space about the vent region. (c) DEM of Karymsky and Dvor Caldera, as viewed from due east, showing the same source locations as in (b). The cluster forms a vertical column, leaning slightly away from the sensor network with increasing altitude. The average elevation of the cluster is $\sim 330 \mathrm{~m}$ above the vent. 


\subsection{Semblance}

In contrast to the srcLoc method, the semblance method uses a fixed sound speed and is thus a useful means of determining error associated with velocity estimation. Fig. 9 compares the semblance results for explosion 1 using two sound speeds. Fig. 9a shows a slice of the stacked semblance output containing the maximum semblance value, $S_{m}$, using the velocity determined by srcLoc, $c=316 \mathrm{~m} / \mathrm{s}$. This semblance map is compared against the location determined by srcLoc (white triangle), with the two methods in good agreement for this value of $c$. Fig. $9 \mathrm{~b}$ shows the same analysis, using a more realistic velocity estimate of $340 \mathrm{~m} / \mathrm{s}$. The location of $S_{m}$ drops significantly, to a region within about $140 \mathrm{~m}$ of the vent. This location appears more reasonable, but results in a slightly lower peak semblance value. The values of $S_{m}$ are 0.38 and 0.33 for the two velocities of 316 and $340 \mathrm{~m} / \mathrm{s}$, respectively. These stacked semblance values represent excellent correlation in both cases, corresponding to raw semblance values of 0.91 and 0.89 , respectively. Thus, the best overall correlation of waveforms occurs for the lower velocity, which is why the srcLoc algorithm uses this velocity and determines a source location that is unrealistic.
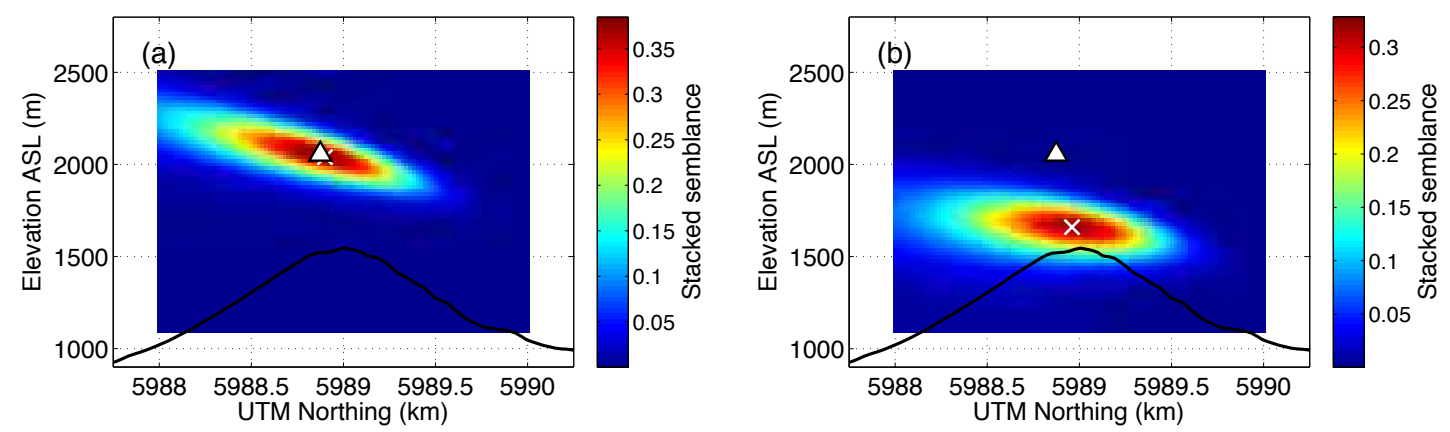

Figure 9. Comparison of 3D acoustic locations for the srcLoc and semblance methods.

Color maps show a slice of the semblance distribution in the northing-elevation plane, white $x$ 's indicate the location of $S_{m}$, and white triangles show the source location as determined by srcLoc. (a) Semblance map for explosion 1 using the velocity determined by srcLoc for this event, $c=316 \mathrm{~m} / \mathrm{s}$. The two methods are in excellent agreement in all three dimensions. (b) Semblance map for explosion 1, using a more realistic sound speed of $340 \mathrm{~m} / \mathrm{s}$. The semblance location is now $140 \mathrm{~m}$ directly above the vent. In horizontal space, the semblance location is now nearly identical to that of the srcLoc result for explosion 2 , as shown in Figure 7a (blue triangle). 

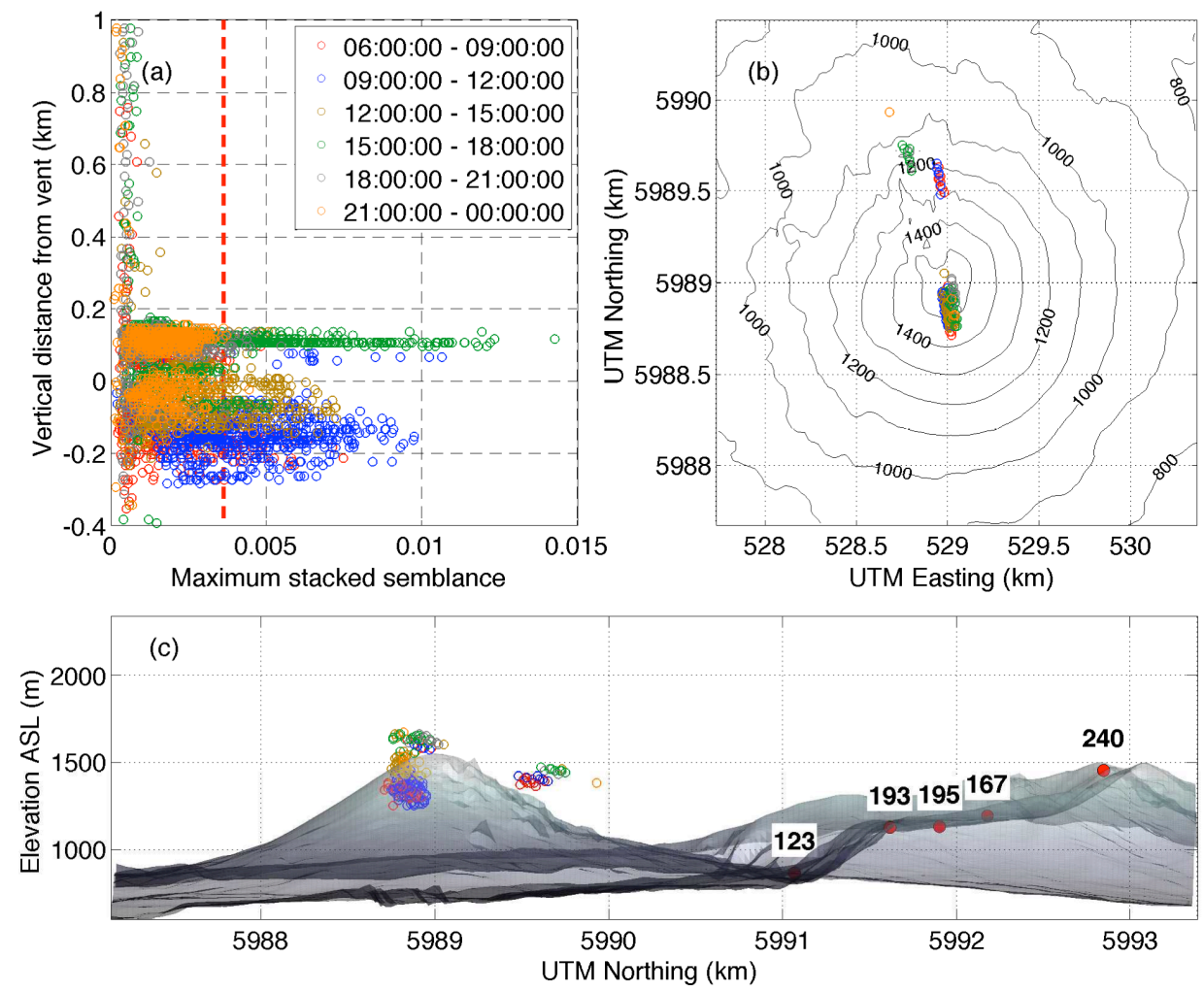

Figure 10. Locations and correlation values for a semblance scan over $18 \mathrm{~h}$ of jetting activity on July 21, using a fixed sound speed of $340 \mathrm{~m} / \mathrm{s}$.

This figure provides a direct comparison to the srcLoc results in Figure 8. (a) Maximum stacked semblance versus vertical error. As in Figure 8a, 0 on the y-axis corresponds to the reference vent elevation. The new locations now cluster directly about the vent elevation. The red, dashed line marks the "detection" threshold; windows with values above this number are plotted in parts (b) and (c). The threshold was chosen at 0.0036 , equivalent to a normalized semblance value of 0.57 . (b) Semblance locations in map view. As for srcLoc, the locations cluster in the vicinity of the vent, with the greatest error in the northsouth and up-down dimensions. (c) Semblance locations in profile view show the concentration of events about the summit.

The semblance method was applied to the jetting data set in a similar manner to srcLoc. Fig. 10 shows the locations of $S_{m}$ for the same 18-hour time period as in Fig. 8, using a sound speed of $340 \mathrm{~m} / \mathrm{s}$. Fig. 10a shows $S_{m}$ plotted against source elevation relative to the vent. The bulk of solutions now cluster in a region centered on the vent. Figs. 10b and 10c show these locations in physical space. The scatter of locations above and below the volcano summit is comparable to scatter in the srcLoc cluster, and can be attributed to random noise in the data. This comparison illustrates how the anomalously high locations from srcLoc can be corrected using a fixed velocity. However, this does not explain the original source of the error. 
Fixing the sound speed to a specific value and using a location grid limits the freedom of the solutions since the solution is approximated rather than calculated analytically. Source locations are reduced to the summit region at the cost of slightly lower signal coherency. The effects of this lower coherency are more pronounced in the jetting locations. For the higher frequency signals, a given time lag error results in a greater phase difference between aligned signals and thus poorer signal correlation. The end result is a general source region approximately $80 \times 340 \times 420 \mathrm{~m}$ in the east, north, and vertical dimensions, respectively. With the peak frequency of jetting signals at $\sim 20 \mathrm{~Hz}$, signal coherency is expected to be limited over distances of a few kilometers, which is likely a significant contributor to the scatter in locations for both the srcLoc and semblance techniques for jetting signals. This suggests we are not able to resolve elevated jet noise sources given this data set. However, such observations may be possible for similar network geometries in the case of volcanic jetting events of larger scale. Large volcanic jets will likely have a greater separation between the vent and peak jet noise source, since this distance is observed to scale upwards with both jet diameter and velocity (Tam et al., 2008). For example, a volcanic jet with a diameter on the order of $100 \mathrm{~m}$, and velocities of $\sim 150 \mathrm{~m} / \mathrm{s}$ might be expected to have a peak jet noise source region $500 \mathrm{~m}$ above the vent (Fig. 3). In addition, larger jets would inherently produce infrasound at lower frequencies, leading to better correlation between sensors. However, larger events would likely have increasingly distributed sources moving at higher velocities, rendering assumptions such as those used by srcLoc increasingly invalid. In addition, sustained eruptions would produce not only sound from the jet itself, but also likely through interactions with the vent and crater walls. Thus, any techniques used in the future to observe volcanic jet noise will likely need to account for multiple, distributed, time evolving sources. Jones and Johnson (2011) suggest that the semblance method has such capability, and other methods used in man-made jet studies for detecting distributed noise sources, such as the spectral estimation techniques of Papamoschou (2011), might also be adapted for use with volcanic networks. 


\subsection{Discussion of errors}

We have shown that 3D location inversions for volcano acoustic signals recorded at Karymsky Volcano in 2012 exhibit a persistent error in time lag estimation that leads to overestimation of source elevation and underestimation of acoustic velocity. Despite this, locations in horizontal space show good accuracy for both location methods. As discussed in Section 5.2, the semblance method can force solutions to a more realistic source location by simply fixing the acoustic velocity, $c$, to a realistic value, at the cost of overall lower signal coherency. While analysis of these errors has not led to the identification of any definitive cause, we speculate on potential causes. Both semblance and cross-correlation rely on the assumption that waveforms are essentially the same across all channels, and not heavily influenced by path effects. Since the simulated data produce correct locations from the srcLoc algorithm, it seems likely that this error originates in a violation of one or more of the assumptions of srcLoc which the simulations do not account for. Given the consistency of this time offset across such a wide variety of signals and atmospheric wind and temperature conditions, the most obvious candidate is the interference of topography with signal propagation. Since several of the sensors lie within the topographic depression of Dvor Caldera (Fig. 1), it is plausible that reverberations from inward facing caldera walls could cause signal interference of waveforms, leading to erroneous cross-correlation lags. However, all sensors lie in positions with line-of-sight to the summit of Karymsky, and the erroneous time lags associated with elevated source locations are correlated with explosion onset times. Waveform distortion from complex reflection patterns within Dvor Caldera would be expected to only influence later parts of signals, while the explosion onset should reflect the true direct source-receiver path. The time lags used by srcLoc for explosion 1 are based on the correlation of the strong initial impulse, and thus are not likely influenced by noisy reverberations or multiple arrivals. More surprisingly, hand picking the explosion onset for explosion 2 leads to an elevated source location similar to that of explosion 1. This event has a much more complex waveform than explosion 1 (Fig. 4), and is more varied across the network. Cross-correlation averages the alignment across 
the full waveform and produces a source location at the vent. Thus, if topographyinduced path effects are occurring, they must influence the waveform before it arrives at the sensors. The most likely explanation remaining is interference due to Karymsky crater itself.
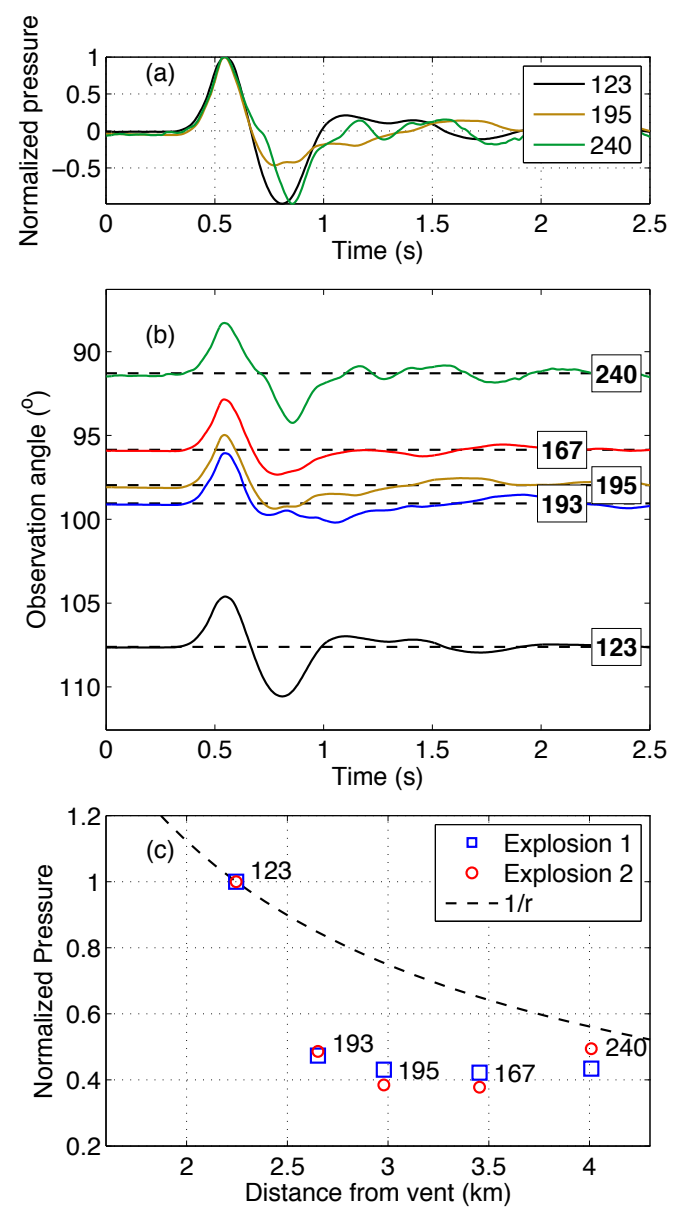

Figure 11. Evidence for strong influence on Karymsky explosion waveforms by crater/topography diffraction effects.

(a) Three channels for explosion 1 are superimposed, amplitude normalized, and aligned by first peak, illustrating the distortion of the initial rarefaction between channels. The rarefaction for sensor 195 is supressed relative to the other two, and the rarefaction for sensor 240 is delayed relative to the other two. (b) Waveforms for explosion 1 adjusted for observation angle, $\theta$, to Karymsky crater. Observation angle can be considered a proxy for receiver elevation. The three middle sensors at similar observation angles show similar suppression of rarefactions, while the top and bottom sensors show different rarefaction features altogether. It is unclear whether the difference in first rarefaction is a consequence of observation angle to the vent or local topography around the sensors. (c) Peak amplitude of explosions bandpassed from 0.2 to $20 \mathrm{~Hz}$ plotted with distance for each channel. Both explosions show a similar amplitude pattern that does not follow a $1 / r$ decay rate. This is highly reminiscent of amplitude suppression observed in Lacanna and Ripepe (2013). Kim and Lees (2011) suggest this effect is due to overlapping crater rim diffraction waves. 
Recent studies have illustrated that near-source topographic effects can have a strong influence on recorded volcano acoustic signals. Kim and Lees (2011) modeled diffraction of acoustic waves around the crater rim of Karymsky Volcano, and Lacanna and Ripepe (2013) examine the amplitude effects of diffraction around topographic features at Stromboli Volcano. Comparison of our explosion data with observations from these studies gives strong qualitative evidence that topography or crater rim geometry is influencing the observed waveforms and time delays. Fig. 11 outlines some of these observations, with Fig. 11a displaying three channels from explosion 1 with normalized amplitudes, superimposed and time aligned to the explosion onset. While the first peak shows a fairly similar shape, the subsequent rarefactions show evidence of complex distortion. For sensor 195, the rarefaction is strongly suppressed. This is true for sensors 167 and 193 as well. The rarefaction for sensor 240 is not supressed but appears delayed or stretched in time. Lacanna and Ripepe (2013) document similar effects, and Kim and Lees (2011) suggest they are due to overlapping diffraction waves around the crater rim.

Models show that crater rim diffraction becomes more significant for increasing frequency and observation angle, $\theta$ (K. Kim, unpublished data, 2011). Fig. 11b shows all five channels for explosion 1 , adjusted on the vertical axis for $\theta$. Counterintuitively, sensor 123 appears to show the least amount of distortion despite having the largest observation angle and being at a receiver site with the most complex local topography (Fig. 1). The reason for this is unclear, though we speculate this may be due to phasealigned overlap of diffraction waves (Kim and Lees, 2011). In a separate test, we systematically reduced the upper frequency limit of the bandpass filter and compared the resulting locations. However, we found that only exceedingly low frequency cutoffs, well into the peak signal frequency range $(<3 \mathrm{~Hz})$, caused significant changes to the source locations. These changes in location were not stable, and are thus more likely a result of phase distortion due to excessive filtering than the removal of diffraction effects. This indicates that simply low-pass filtering cannot mitigate the diffraction effects for our signals at Karymsky. The diffraction features presented in Figs. 11a and 11b are also present in the explosion 2 data, but are less visually apparent due to the complexity of the 
waveform. The final evidence for crater rim diffraction effects in the waveforms can be seen in the amplitude relationships for both explosions. Fig. 11c shows the normalized maximum amplitude of waveforms plotted with receiver slant distance from Karymsky's vent. Both explosions show a similar pattern of relative amplitudes that strongly diverges from the expected far-field $1 / r$ decay relationship. Lacanna and Ripepe (2013) showed that interference from local topography could have a strong influence on recorded amplitudes, and document a strikingly similar amplitude vs. distance relationship.

These combined observations support the idea that explosions recorded from Karymsky Volcano (and potentially other volcanoes) are strongly influenced by acoustic diffraction or reflection from the crater rim. Both of the modeling studies discussed here indicate that topography and diffraction must be taken into consideration before interpreting source physics. However, it is not clear why an effect such as crater rim diffraction should alter the timing of wavefront arrivals, though the consistency of elevated source locations in this study suggests that this may be the case. Alternatively, the shape of Karymsky's summit could force raypaths to diffract around a larger portion of the edifice to reach lower elevations. This would lead to greater time delays at larger observation angles. It is not clear if this would occur for Karymsky's relatively simple shape, but this effect would generally agree with the observed pattern of time delays across the network. Whether time delays are caused by crater diffraction or varying raypaths, this has clear implications for any attempt to accurately locate volcanic sources in $3 \mathrm{D}$ or perform source inversions. To do so would require detailed understanding of crater geometry, and how topography can alter signals arriving at sensor sites. Diffraction directionality and frequency dependence, in particular, would be of paramount importance for any network with significant vertical distribution. Unfortunately, understanding the nature of these influences requires detailed modeling and observations beyond the scope of this study. It is worth noting that for a jet noise source elevated above the crater, no such rim diffraction would be present. However, overlap of signals from both the vent and a turbulent jet may complicate observed waveforms. 


\section{Conclusions}

Two 3-D acoustic source localization methods were utilized on acoustic signals from Karymsky Volcano. The signals had widely varying frequency, duration, and SNR. Testing of the srcLoc algorithm for locating volcano-acoustic sources in 3-D has shown that it is a highly computationally efficient method, capable of locating acoustic sources with high precision much faster than real-time on a standard desktop computer. High frequency jetting during this study provided a difficult testing scenario, due to low SNR and low coherency in high-frequency signals separated by distances of a few kilometers. In this difficult scenario, srcLoc is able to produce locations in horizontal dimensions to within $200 \mathrm{~m}$, and simulations show that for well-correlated signals with good SNR, accuracies of $50 \mathrm{~m}$ or better are possible. At Karymsky, large location errors in the vertical dimension point to conditions that violate the assumptions of srcLoc. Complex source or path effects may be a significant problem for ground-based networks with inherently low vertical-to-horizontal aspect ratios.

Comparing results from the grid-search based semblance location method to srcLoc revealed that fixing the sound speed to standard atmospheric velocities provides more realistic source locations at the cost of a coarser approximation to the solution, resulting in overall lower signal coherency. Previous studies suggest this method is also capable of resolving multiple and/or distributed, time evolving sources (Jones and Johnson, 2011). This is of particular importance in application to locating jet noise from large volcanic events, where sources are likely to be distributed and non-stationary.

The consistency of hundreds of overestimated srcLoc elevations suggest a systematic source of error that does not vary with wind and temperature conditions. Explosion waveforms show a variety of features that suggest signal interference from topography or crater rim diffractions. These features include suppression of first rarefactions, stretching of waveforms, and amplitude decay relationships that do not conform to a $1 / r$ spreading loss. Recent studies modeling crater rim and topographic diffraction effects are in good agreement with these observations (Kim and Lees, 2011; Lacanna and Ripepe, 2013). 
Given that all acoustic sensors in our network had line-of-site observation to the Karymsky summit, the crater rim is the most likely source of diffraction effects.

Both of these location methods appear sufficient to locate volcano acoustic sources in 3-D, which may aid in research and hazard mitigation through tracking of activity along fissures or multiple-vent systems, particularly in areas with significant topographic relief. While the combination of relatively low-level eruptions, network geometry and localization methods presented here are insufficient to image elevated sources of turbulent volcanic jet noise, the foundation has been established for future studies of this type. In particular, observation of volcanic jet noise will require volcanic jetting of sufficient magnitude combined with a network of sensors in 3-D distribution to provide resolution in the vertical dimension. Given such a data set, an acoustic localization method must be used that is capable of considering distributed noise sources. Finally, modeling analysis for 3-D acoustic arrays at volcanoes is necessary to determine if TDOA information is altered by topographic influences, particularly at varying sourcereceiver observation angle.

\section{References}

Almendros, J. and Chouet, B., 2003. Performance of the radial semblance method for the location of very long period volcanic signals, Bulletin of the Seismological Society of America 93 (5), 1890-1903.

Arnoult, K., Szuberla, C. A. L., and Olson, J. V., 2010. Method and system for conducting near-field source localization, US Patent 7746225.

Cannata, A., Montalto, P., Privitera, E., Russo, G., and Gresta, S., 2009. Tracking eruptive phenomena by infrasound: May 13, 2008 eruption at Mt. Etna, Geophys. Res. Lett. 36 (5), L05304.

Cannata, A., Montalto, P., Aliotta, M., Cassisi, C., Pulvirenti, A., Privitera, E., and Patanè, D., 2011. Clustering and classification of infrasonic events at Mount Etna using pattern recognition techniques, Geophysical Journal International 185 (1), 253-264. 
Caplan-Auerbach, J., Bellesiles, A., and Fernandes, J. K., 2010. Estimates of eruption velocity and plume height from infrasonic recordings of the 2006 eruption of Augustine Volcano, Alaska, J. Volcanol. Geotherm. Res. 189 (1-2), 12-18.

Chu, W. T. and Kaplan, R. E., 1976. Use of a spherical concave reflector for jet-noisesource distribution diagnosis, J. Acoust. Soc. Am. 59 (6), 1268-1277.

Crow, S. C. and Champagne, F. H., 1971. Orderly structure in jet turbulence, J. Fluid Mech. 48 (03), 547.

Dawson, P., Whilldin, D., and Chouet, B., 2004. Application of near real-time radial semblance to locate the shallow magmatic conduit at Kilauea Volcano, Hawaii, Geophys. Res. Lett. 31 (21), L21606.

DiBiase, J. H., Silverman, H. F., and Brandstein, M. S., 2001. Robust localization in reverberant rooms, in Microphone Arrays, edited by M. S. Brandstein and D. Ward, pp. 157-180, Springer.

Fee, D. and Garcés, M., 2007. Infrasonic tremor in the diffraction zone, Geophys. Res. Lett. 34 (16), L16826.

Fee, D., Garces, M., and Steffke, A., 2010a. Infrasound from Tungurahua Volcano 2006-2008: Strombolian to Plinian eruptive activity, J. Volcanol. Geotherm. Res. 193 $(1-2), 67-81$.

Fee, D., Steffke, A., and Garces, M., 2010b. Characterization of the 2008 Kasatochi and Okmok eruptions using remote infrasound arrays, Journal of Geophysical Research: Atmospheres 115 (D2), D00L10.

Fee, D. and Matoza, R. S., 2013. An overview of volcano infrasound: From hawaiian to plinian, local to global, J. Volcanol. Geotherm. Res. 249, 123-139.

Fee, D., Matoza, R. S., Gee, K. L., Neilsen, T. B., and Ogden, D. E., 2013. Infrasonic crackle and supersonic jet noise from the eruption of Nabro Volcano, Eritrea, Geophys. Res. Lett., 4199-4203.

Firstov, P. P., Fee, D., and Makhmudov, E. R., 2013. The explosive activity of Karymskii Volcano, Kamchatka: Acoustic and seismic observations 7 (4), 252-264.

Fischer, T. P., Roggensack, K., and Kyle, P. R., 2002. Open and almost shut case for explosive eruptions: Vent processes determined by SO2 emission rates at Karymsky volcano, Kamchatka, Geology 30 (12), 1059-1062. 
Garcés, M., Harris, A., Hetzer, C., Johnson, J., Rowland, S., Marchetti, E., and Okubo, P., 2003. Infrasonic tremor observed at Kilauea Volcano, Hawai'i, Geophys. Res. Lett. 30 (20), 2023.

Gauntner, J. W., Livingood, J. N. B., Hrycak, P., United States. National Aeronautics, Space Administration, and Lewis Research Center, 1970. Survey of Literature on Flow Characteristics of a Single Turbulent Jet Impinging on a Flat Plate: By James W. Gauntner, John N.B. Livingood, and Peter Hrycak, National Aeronautics and Space Administration.

Gee, K. L., Sparrow, V. W., Atchley, A. A., and Gabrielson, T. B., 2007. On the perception of crackle in high-amplitude jet noise, AIAA J. 45 (3), 593-598.

Gordeev, E., Kasahara, M., Levina, V., Miyamachi, H., and Chebrov, V., 1997. Magma activity at Karymsky Volcano and Academy Nauk Caldera (Kamchatka, Russia) triggers large tectonic (M7. 0) event, Eos Trans. Am. Geophys. Union 78, 442.

Ivanov, B., Braitseva, O., and Zubin, M., 1991. Karymsky volcano, in Active Volcanoes of Kamchatka, vol. 2, edited by S. A. Fedotov and Y. P. Masurenkov, pp. 181-203, Nauka, Moscow.

Izbekov, P. E., Eichelberger, J. C., and Ivanov, B. V., 2004. The 1996 eruption of Karymsky Volcano, Kamchatka: historical record of basaltic replenishment of an andesite reservoir, Journal of Petrology 45 (11), 2325-2345.

Johnson, D. H. and Dudgeon, D. E., 1993. Array Signal Processing - Concepts and Techniques, Prentice Hall.

Johnson, J. B. and Lees, J. M., 2000. Plugs and chugs - seismic and acoustic observations of degassing explosions at Karymsky, Russia and Sangay, Ecuador, J. Volcanol. Geotherm. Res. 101 (1-2), 67-82.

Johnson, J. B., Aster, R. C., Ruiz, M. C., Malone, S. D., McChesney, P. J., Lees, J. M., and Kyle, P. R., 2003. Interpretation and utility of infrasonic records from erupting volcanoes, J. Volcanol. Geotherm. Res. 121 (1-2), 15-63.

Johnson, J. B., Anderson, J., Marcillo, O., and Arrowsmith, S., 2012. Probing local wind and temperature structure using infrasound from Volcan Villarrica (Chile), Journal of Geophysical Research: Atmospheres 117 (D17), D17107.

Johnson, J. B., Lees, J. M., and Gordeev, E. I., 1998. Degassing explosions at Karymsky Volcano, Kamchatka, Geophys. Res. Lett. 25 (21), 3999-4002. 
Johnson, J. B., 2007. On the relation between infrasound, seismicity, and small pyroclastic explosions at Karymsky Volcano, J. Geophys. Res. 112 (B8), B08203.

Jones, K. R. and Johnson, J. B., 2011. Mapping complex vent eruptive activity at Santiaguito, Guatemala using network infrasound semblance, J. Volcanol. Geotherm. Res. 199 (1-2), 15-24.

Jones, K. R., Johnson, J. B., Aster, R., Kyle, P. R., and McIntosh, W. C., 2008. Infrasonic tracking of large bubble bursts and ash venting at Erebus Volcano, Antarctica, J. Volcanol. Geotherm. Res. 177 (3), 661-672.

Karabasov, S. A., 2010. Understanding jet noise, Philosophical Transactions of the Royal Society A: Mathematical, Physical and Engineering Sciences 368 (1924), 3593-3608.

Kim, K. and Lees, J. M., 2011. Finite-difference time-domain modeling of transient infrasonic wavefields excited by volcanic explosions, Geophys. Res. Lett. 38 (6), L06804.

Lacanna, G. and Ripepe, M., 2013. Influence of near-source volcano topography on the acoustic wavefield and implication for source modeling, J. Volcanol. Geotherm. Res. 250, 9-18.

Lees, J. M., Gordeev, E. I., and Ripepe, M., 2004. Explosions and periodic tremor at Karymsky volcano, Kamchatka, Russia, Geophysical Journal International 158 (3), 11511167.

Lighthill, M. J., 1952. On sound generated aerodynamically. I. General theory, Proceedings of the Royal Society of London, Series A: Mathematical and Physical Sciences 211 (1107), 564-587.

Lighthill, M. J., 1954. On sound generated aerodynamically. II. Turbulence as a source of sound, Proceedings of the Royal Society of London, Series A: Mathematical and Physical Sciences 222 (1148), 1-32.

Lopez, T., Fee, D., Prata, F., and Dehn, J., 2013. Characterization and interpretation of volcanic activity at Karymsky Volcano, Kamchatka, Russia, using observations of infrasound, volcanic emissions, and thermal imagery, Geochem. Geophys. Geosyst. 14.

Matoza, R. S., Fee, D., Garcés, M. A., Seiner, J. M., Ramón, P. A., and Hedlin, M. A. H., 2009a. Infrasonic jet noise from volcanic eruptions, Geophys. Res. Lett. 36 (8), L08303. 
Matoza, R. S., Garcés, M. A., Chouet, B. A., D'Auria, L., Hedlin, M. A. H., De GrootHedlin, C., and Waite, G. P., 2009b. The source of infrasound associated with longperiod events at Mount St. Helens, Journal of Geophysical Research: Solid Earth 114 (B4), B04305.

Matoza, R. S., Le Pichon, A., Vergoz, J., Herry, P., Lalande, J., Lee, H., Che, I., and Rybin, A., 2011. Infrasonic observations of the June 2009 Sarychev Peak eruption, Kuril Islands: Implications for infrasonic monitoring of remote explosive volcanism, J. Volcanol. Geotherm. Res. 200 (1-2), 35-48.

Matoza, R. S., Fee, D., Neilsen, T. B., Gee, K. L., and Ogden, D. E., in press. Aeroacoustics of volcanic jets: Acoustic power estimation and jet velocity dependence, J. Geophys. Res.

Montalto, P., Cannata, A., Privitera, E., Gresta, S., Nunnari, G., and Patanè, D., 2010. Towards an automatic monitoring system of infrasonic events at Mt. Etna: strategies for source location and modeling, Pure Appl. Geophys. 167 (10), 1215-1231.

Neidell, N. S. and Taner, M. T., 1971. Semblance and other coherency measures for multichannel data, Geophysics 36 (3), 482-497.

Olson, J. V. and Szuberla, C. A., 2009. Processing infrasonic array data, in Handbook of Signal Processing in Acoustics, edited by D. Havelock, S. Kuwano, and M. Vorlander, pp. 1487-1496, Springer.

Ozerov, A., Ispolatov, I., and Lees, J., 2003. Modeling Strombolian eruptions of Karymsky volcano, Kamchatka, Russia, J. Volcanol. Geotherm. Res. 122 (3-4), 265-280.

Papamoschou, D., 2011. Imaging of directional distributed noise sources, J. Sound Vibrat. 330 (10), 2265-2280.

Parfitt, E. A. and Wilson, L., 2008. Fundamentals of Physical Volcanology, Bulletin of Volcanology, Blackwell Publishing, Oxford.

Press, W. H., Teukolsky, S., Vetterling, W., and Flannery, B., 1992. Numerical recipes in C: the art of scientific computing, 994.

Ripepe, M. and Marchetti, E., 2002. Array tracking of infrasonic sources at Stromboli volcano, Geophys. Res. Lett. 29 (22), 2076.

Ripepe, M., Bonadonna, C., Folch, A., Delle Donne, D., Lacanna, G., Marchetti, E., and Höskuldsson, A., 2013. Ash-plume dynamics and eruption source parameters by infrasound and thermal imagery: The 2010 Eyjafjallajökull eruption, Earth Planet. Sci. Lett. 366, 112-121. 
Ripepe, M., De Angelis, S., Lacanna, G., and Voight, B., 2010. Observation of infrasonic and gravity waves at Soufrière Hills Volcano, Montserrat, Geophys. Res. Lett. 37, L00E14.

Schlinker, R. H., Reba, R. A., Simonich, J. C., Colonius, T., Gudmundsson, K., and Ladeinde, F., 2009. Towards prediction and control of large-scale turbulent structure supersonic jet noise, Proceedings of ASME Turbo Expo, Orlando, Fl., USA.

Szuberla, C. A. L. and Arnoult, K., 2011. Locating explosions, volcanoes, and more with infrasound, Phys Today 64 (4), 74.

Szuberla, C. A. L., Arnoult, K. M., and Olson, J. V., 2006. Discrimination of near-field infrasound sources based on time-difference of arrival information, J. Acoust. Soc. Am. 120 (3), EL23-EL28.

Szuberla, C. A. L., Olson, J. V., and Arnoult, K. M., 2009. Explosion localization via infrasound, J. Acoust. Soc. Am. 126 (5), EL112-EL116.

Tam, C., Golebiowski, M., and Seiner, J., 1996. On the two components of turbulent mixing noise from supersonic jets, Aeroacoustics Conferences, AIAA Pap., State College, Pa., USA.

Tam, C. K. W., 1998. Jet Noise: Since 1952, Theoret. Comput. Fluid Dynamics 10 (14), 393-405.

Tam, C. K. W., Pastouchenko, N. N., and Schlinker, R. H., 2006. Noise source distribution in supersonic jets, J. Sound Vibrat. 291 (1-2), 192-201.

Tam, C. K. W., Viswanathan, K., Ahuja, K. K., and Panda, J., 2008. The sources of jet noise: experimental evidence, J. Fluid Mech. 615, 253.

Thomas, C., 2009. Array signal processing, in Handbook of Signal Processing in Acoustics, edited by D. Havelock, S. Kuwano, and M. Vorlander, pp. 1655-1665, Springer.

Vergniolle, S. and Caplan-Auerbach, J., 2006. Basaltic thermals and Subplinian plumes: Constraints from acoustic measurements at Shishaldin volcano, Alaska 68 (7-8), 611-630.

Viswanathan, K., 2009. Mechanisms of jet noise generation: classical theories and recent developments, International Journal of Aeroacoustics 8 (4), 355-407.

Woulff, G. and McGetchin, T. R., 1976. Acoustic Noise from Volcanoes: Theory and Experiment, Geophysical Journal of the Royal Astronomical Society 45 (3), 601-616. 